This document is confidential and is proprietary to the American Chemical Society and its authors. Do not copy or disclose without written permission. If you have received this item in error, notify the sender and delete all copies.

\title{
Engineered pH-Responsive Mesoporous Carbon Nanoparticles for Drug Delivery
}

\begin{tabular}{|c|c|}
\hline Journal: & ACS Applied Materials \& Interfaces \\
\hline Manuscript ID & am-2020-01786a.R1 \\
\hline Manuscript Type: & Article \\
\hline $\begin{array}{r}\text { Date Submitted by the } \\
\text { Author: }\end{array}$ & 03-Mar-2020 \\
\hline Complete List of Authors: & $\begin{array}{l}\text { Gisbert-Garzarán, Miguel; Universidad Complutense de Madrid, } \\
\text { Departamento de química en ciencias farmacéuticas, Unidad de química } \\
\text { inorgánica y bioinorgánica; CIBER-BBN } \\
\text { Berkmann, Julia; Charité Universitätsmedizin Berlin, Julius Wolff Institute } \\
\text { and Center for Musculoskeletal Surgery; Charité Universitätsmedizin } \\
\text { Berlin, Berlin-Brandenburg School for Regenerative Therapies } \\
\text { Giasafaki, Dimitra; National Centre for Scientific Research-Demokritos } \\
\text { Lozano, Daniel; Universidad Complutense de Madrid, Departamento de } \\
\text { química en ciencias farmacéuticas, Unidad de química inorgánica y } \\
\text { bioinorgánica; CIBER-BBN } \\
\text { Spyrou, Konstantinos; University of Ioannina School of Sciences and } \\
\text { Technology, Material Science and Engineering } \\
\text { Manzano, Miguel; Universidad Complutense de Madrid, Departamento de } \\
\text { química en ciencias farmacéuticas, Unidad de química inorgánica y } \\
\text { bioinorgánica; CIBER-BBN } \\
\text { Steriotis, Theodore A.; National Centre for Scientific Research- } \\
\text { Demokritos } \\
\text { Duda, Georg; Charité Universitätsmedizin Berlin, Julius Wolff Institute } \\
\text { and Center for Musculoskeletal Surgery; Charité Universitätsmedizin } \\
\text { Berlin, Berlin-Brandenburg School for Regenerative Therapies; Charité } \\
\text { Universitätsmedizin Berlin, Berlin Institute of Health Center for } \\
\text { Regenerative Therapies } \\
\text { Schmidt-Bleek, Katharina; Charité Universitätsmedizin Berlin, Julius } \\
\text { Wolff Institute and Center for Musculoskeletal Surgery; Charité } \\
\text { Universitätsmedizin Berlin, Berlin-Brandenburg School for Regenerative } \\
\text { Therapies } \\
\text { Charalambopoulou, Georgia; National Centre for Scientific Research- } \\
\text { Demokritos } \\
\text { Vallet-Regí, María; Universidad Complutense de Madrid, Departamento } \\
\text { de química en ciencias farmacéuticas, Unidad de química inorgánica y } \\
\text { bioinorgánica; CIBER-BBN }\end{array}$ \\
\hline
\end{tabular}

\section{SCHOLARONE ${ }^{\text {IM }}$ Manuscripts}




\section{Engineered pH-Responsive Mesoporous Carbon}

\section{Nanoparticles for Drug Delivery}

Miguel Gisbert-Garzarán, ${ }^{1,2 \ddagger}$ Julia C. Berkmann, ${ }^{3,4 \ddagger}$ Dimitra Giasafaki, ${ }^{5}$ Daniel Lozano, ${ }^{1,2}$

Konstantinos Spyrou, ${ }^{6}$ Miguel Manzano, ${ }^{1,2}$ Theodore Steriotis, ${ }^{5}$ Georg N. Duda, ${ }^{3,4,7}$

Katharina Schmidt-Bleek, ${ }^{3,4 *}$ Georgia Charalambopoulou, ${ }^{5 *}$ and María Vallet-Regi ${ }^{1,2 *}$

${ }^{1}$ Department of Chemistry in Pharmaceutical Sciences, Faculty of Pharmacy,

Universidad Complutense de Madrid, Instituto de Investigación Sanitaria Hospital 12 de

Octubre (imas12), Plaza Ramón y Cajal s/n, 28040 Madrid, Spain.

${ }^{2}$ Networking Research Center on Bioengineering, Biomaterials and Nanomedicine

(CIBER-BBN), Madrid, Spain.

3Julius Wolff Institute and Center for Musculoskeletal Surgery, Charité-

Universitätsmedizin Berlin, Berlin, Germany. 


\author{
${ }^{4}$ Berlin-Brandenburg School for Regenerative Therapies, Charité — Universitätsmedizin \\ Berlin, Berlin, Germany.
}

${ }^{5}$ National Center for Scientific Research "Demokritos", 15341 Agia Paraskevi Attikis,

\author{
Athens, Greece. \\ ${ }^{6}$ Department of Materials Science and Engineering, University of loannina, GR-45110 \\ Ioannina, Greece.
}

${ }^{7}$ Berlin Institute of Health Center for Regenerative Therapies, Berlin, Germany.

‡ Both authors contributed equally to this work.

${ }^{*}$ Corresponding authors.

E-mail: Katharina.Schmidt-Bleek@charite.de

E-mail: gchar@ipta.demokritos.gr

E-mail: vallet@ucm.es 


\author{
KEYWORDS: Mesoporous Carbons, pH-responsive, self-immolative coating, drug \\ delivery, controlled release
}

\begin{abstract}
In this work, two types of mesoporous carbon particles with different morphology, size and pore structure have been functionalized with a self-immolative polymer sensitive to changes in $\mathrm{pH}$ and tested as drug nanocarriers. It is shown that their textural properties allow significantly higher loading capacity compared to typical mesoporous silica
\end{abstract} nanoparticles. In via/ release experiments of a model Ru dye at $\mathrm{pH} 7.4$ and 5 confirm the $\mathrm{pH}$-responsiveness of the hybrid systems, showing that only small amounts of the cargo are released at physiological $\mathrm{pH}$, whereas at slightly acidic $\mathrm{pH}$ (e.g. that of lysosomes) self-immolation takes place and a significant amount of the cargo is released. Cytotoxicity studies using human osteosarcoma cells show that the hybrid nanocarriers are not cytotoxic by themselves but induce significant cell growth inhibition when loaded with a chemotherapeutic drug such as doxorubicin. In preparation of an in vivo application, in 
vial responsiveness of the hybrid system to short-term pH-triggering is confirmed. The consecutive in vivo study shows no substantial cargo release over a period of 96 hours under physiological $\mathrm{pH}$ conditions. Short-term exposure to acidic $\mathrm{pH}$ releases an experimental fluorescent cargo during and continuously after the triggering period over

72 hours.

\section{INTRODUCTION}

Recent advances in nanotechnology have provided a new arsenal to modern medicine leading to the development of a new field, nanomedicine, which has inspired more specific and efficient treatments towards the treatment of complex diseases, such as cancer. $^{1-4}$ The benefits of using nanoparticles for drug delivery versus systemic treatments include enhancement of pharmacokinetic profiles, the possibility of releasing therapeutic molecules to specific tissues thus reducing undesirable side effects, and the ability to bypass potential biological barriers. In this sense, nanoparticles acting as delivery vehicles of a variety of pharmaceutical agents currently represent $c a .75 \%$ of the 
market share of approved nanomedicines. ${ }^{5}$ A great variety of nanoparticles have been proposed as nanomedicines, spanning from lipid-based, protein and polymeric nanoparticles as well as polymer-drug conjugates to different inorganic nanoparticles. ${ }^{6-8}$ Among them, mesoporous materials, and in particular mesoporous silica nanoparticles (MSNs), have become very popular as the basis of smart drug nanocarriers because of their outstanding physicochemical properties, including tunable pore size, high pore volume and large surface area, among others, that provide a great storage capacity within the porous network coupled with controlled release of the cargo, due to nanoconfinement. ${ }^{9-15}$ MSNs can easily be loaded using different techniques, such as electrospray or impregnation. ${ }^{16}$

In contrast, mesoporous carbon nanoparticles presenting in general similar structural properties with traditional MSNs, have not been fully explored. Carbon nanoparticles have significant advantages over their silica counterparts with respect to their textural properties, which may translate into drastic benefits regarding their capacity to adsorb various molecules. For example, regular MSNs present specific surface areas and average pore volumes of $c a .1000 \mathrm{~m}^{2} / \mathrm{g}$ and $c a .1$ $\mathrm{cm}^{3} / \mathrm{g}$, respectively. On the other hand, mesoporous carbons offer specific surface areas of $c a$. $2000 \mathrm{~m}^{2} / \mathrm{g}$ and pore volumes of $1.5 \mathrm{~cm}^{3} / \mathrm{g}$. In addition, mesoporous carbons present outstanding biocompatibility, great loading capcity of drugs showing reduced hydrophilicity and provide 
superior loading capacity for aromatic drugs as a consequence of their additional supramolecular $\pi$ - (or pi-) stacking interactions. ${ }^{17-20}$

Although the open internal structure of mesoporous carbon nanoparticles makes them ideal candidates to introduce active compounds, the loaded biomolecules can easily diffuse out when the materials are placed in solution. Thus, closing the pore entrances is essential for the nanocarrier to control the cargo desorption and avoid premature release. One of the most successful approaches for blocking the pore entrances is coating the particle surface with a responsive polymer, so cargo leakage is impeded until some stimulus might change the conformation of the polymer, triggering the cargo release. Such hybrid carriers, known as stimuli-responsive systems, permit to tailor the release profiles of the cargo, enabling thus spatial, temporal and dosage control. Various types of stimuli-responsive mesoporous carbon systems have been developed so far, showing sensitivity to e.g. $\mathrm{pH},{ }^{21-23}$ redox, ${ }^{24,25}$ enzymes, ${ }^{26,27}$ ultrasound, ${ }^{28}$ light, ${ }^{29,30}$ temperature $^{31}$ or magnetic fields. ${ }^{32}$ Among them, pH-responsive mesoporous carbon systems have been investigated the most, because of the ample applications due to the natural $\mathrm{pH}$ gradients that exist between healthy and diseased tissues. In fact, in most tumors, the $\mathrm{pH}$ is lower than the physiologic value (7.4) because of the high rate of glycolysis of cancer cells, which leads to lactic acid accumulation. Additionally, other areas of the body present acidic $\mathrm{pHs}$, such as the gastrointestinal track or some subcellular compartments, such as endosomes or lysosomes. ${ }^{33}$ Some examples of $\mathrm{pH}$-responsive gatekeepers employed to close the pore entrances of mesoporous carbons include biodegradable polymers, ${ }^{26}$ small degradable nanoparticles ${ }^{34,35}$ or large polymers able to change their conformation and open the pores upon changes in the $\mathrm{pH} .{ }^{25,36}$ However, regardless of the number of scientific publications on biomedical applications of mesoporous carbon nanoparticles, this area is still at its infancy, with many significant challenges still to be solved before translation into clinical practice. ${ }^{37}$ 
The primary aim of this work has been to investigate the loading capacity of mesoporous carbon particles and evaluate their potential use as $\mathrm{pH}$-responsive delivery systems. For this purpose, we have developed responsive drug delivery systems based on two mesoporous carbon matrices (CMK-3 and spherical CMK-1) that are functionalized with a self-immolative polyurethane. ${ }^{38}$ Due to their interesting chemical properties, several self-immolative structures have been used in nanomedicine. ${ }^{39}$ In particular, we have used a polyurethane bearing a BOC moiety as end-cap, which provides $\mathrm{pH}$ sensitivity (Scheme 1). At physiological $\mathrm{pH}$, the $\mathrm{pH}$-responsive trigger would preserve its integrity. However, after a drop in $\mathrm{pH}$ to more acidic values, the trigger unit would be cleaved, thus initiating the disassembly of the self-immolative backbone. As a consequence, the pores of the host matrix would be unlocked and the cargo would be released only in acidic environments. This coating approach has been successfully used by the authors for MSNs; ${ }^{40}$ the advantage of using mesoporous carbons relies on the higher loading capacity that can be achieved (especially for the case of poorly soluble active pharmaceutical ingredients, APIs) coupled with the inert carbon surface that minimizes toxic effects. An additional benefit of this approach is the potential colloidal 
stabilization of the particles in aqueous media, a general problem related to unmodified carbon particles.

The $\mathrm{pH}$-responsive release behavior of the two new systems has been demonstrated in vial, in vitro and in vivo. In addition, the selective cytotoxicity of the drug-loaded materials in comparison to the non-loaded ones has been validated in vitro. Finally, in order to lay the grounds for future in vivo applications, an in vivo proof-of-concept trial has been performed in a pre-clinical rodent model. To confirm the in vivo $\mathrm{pH}$-responsiveness, the integrity of the materials under physiological and acidic conditions was investigated, while local reaction towards the particles was monitored to assess the materials' biocompatibility. 

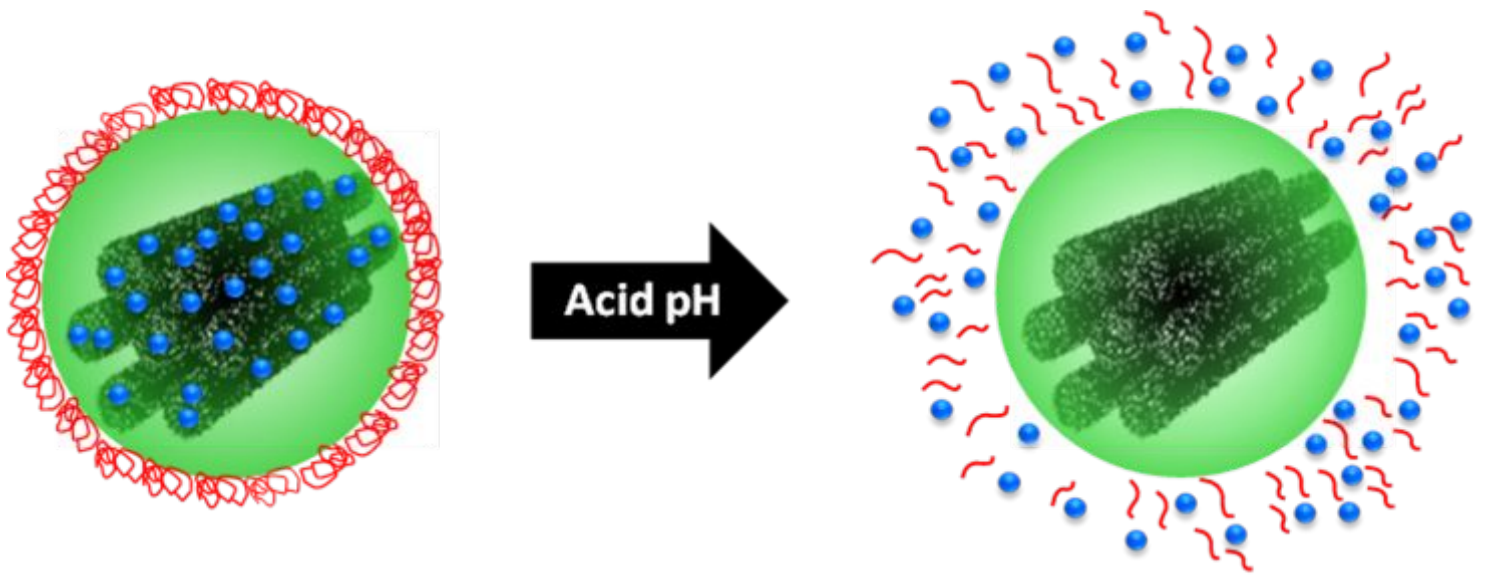

\section{Acid pH}

Payload

$\sim \mathrm{pH}$-responsive Self-Immolative polymer

Scheme 1. Schematic representation of the pH-responsive mesoporous carbons. At neutral $\mathrm{pH}$ the self-immolative coating remains collapsed on the surface. However, when placed in an acid environment, the polymers undergoes self-immolation, leading to the payload release.

\section{RESULTS AND DISCUSSION}

Properties of the as-produced mesoporous carbon carriers. Two different mesoporous carbons (namely CMK-3 and spherical CMK-1, denoted as C3 and C1Sph, respectively) were developed. Each carbon carrier was synthesized through a nanocasting procedure, using silica templates (SBA-15 and spherical MCM-48, respectively) that were removed 
after the generation of the carbon replica. The as-produced mesoporous carbons were characterized by Scanning and Transmission Electron Microscopy (SEM, TEM), $\mathrm{N}_{2}$ porosimetry, Small Angle X-ray Scattering (SAXS) and X-ray Photoelectron Spectroscopy (XPS). (Details are given in the Supporting Information).

As presented in Figure 1A, the rod-like elongated macrostructure characteristic of CMK-3 type carbons was obtained for the $\mathrm{C} 3$ material, ${ }^{41}$ showing a diameter of $0.2-0.3 \mu \mathrm{m}$ and length of $0.5-1$ $\mu \mathrm{m}$. The aligned mesochannels of the $\mathrm{C} 3$ material (Figure 1A, inset) are characteristic of their 2D periodic hexagonal mesostructure. With regard to the C1Sph material, the nanoparticles presented an average size of $c a .150 \mathrm{~nm}$ and spherical morphology (Figure 1B). In addition, the TEM microscopy revealed the expected ordered porous network of the herein synthesized carbon particles (Figure 1C for C3 and Figure 1D for C1Sph). 


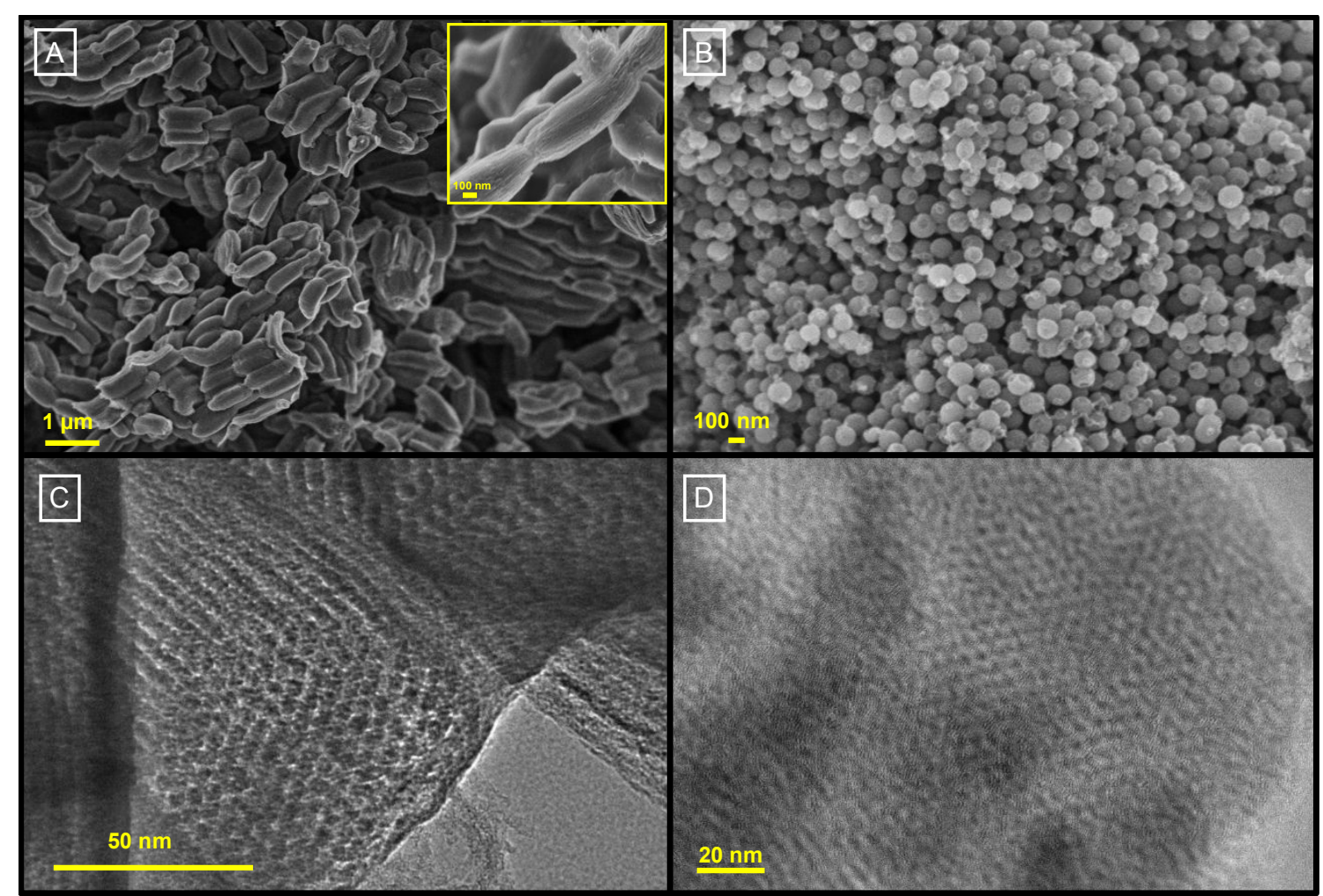

Figure 1. SEM and TEM micrographs of the as-synthesized carbons. A) SEM

micrographs of C3 carbons with rod-like elongated macrostructure. Inset: C3 mesochannels. B) SEM micrographs of C1Sph with well-defined spherical morphology.

C) TEM micrographs of C3. D) TEM micrographs of C1Sph.

The pore network structure of the carbon materials was evaluated through SAXS measurements (Figure S4). The pattern obtained for C3 shows the (10), (11), and (20) reflections characteristic of a $2 \mathrm{D}$ and hexagonally ordered array of pores ( $\left(\mathrm{m} 6 \mathrm{~mm}\right.$ space group) ${ }^{42,43}$ On the other hand, the two well-defined diffraction peaks (110) and (211) in the C1Sph pattern are compatible with the 3-D cubic pore structure $\left(I 4_{1} 32\right.$ space group) of this sample. ${ }^{44}$ 
The porous structure of the carbon materials was analyzed by $\mathrm{N}_{2}$ adsorption-desorption measurements at $77 \mathrm{~K}$ (Figure S5), revealing their excellent textural properties (see Table 1 and Supporting Information for further details). In brief, C3 has a mean pore size of $4.5 \mathrm{~nm}$, a BET area of $1340 \mathrm{~m}^{2} \mathrm{~g}^{-1}$ and a total (micro- and meso-) pore volume of $1.4 \mathrm{~cm}^{3} \mathrm{~g}^{-1}$, while $\mathrm{C} 1 \mathrm{Sph}$ (mean pore size $3.2 \mathrm{~nm}$ ) displays a BET area of $1650 \mathrm{~m}^{2} \mathrm{~g}^{-1}$ and a total pore volume of $1.2 \mathrm{~cm}^{3}$ $\mathrm{g}^{-1}$.

Loading capacity of the as-produced mesoporous carbon carriers. A model ruthenium complex was loaded in conventional MSNs and in both carbon carriers to evaluate whether their remarkable textural properties translated into a higher loading capacity. Indeed, thermogravimetric analyses (TGA) revealed that the C3 and C1Sph mesoporous carbons could accommodate significant quantities of Ru dye. For the case of C1Sph, the amount of Ru molecules is almost three times higher than that adsorbed by conventional MSNs, which were used as reference (Figure 2). The obtained data confirm that the storage capacity is related to the material surface area, as initially assumed. Furthermore, it can be concluded that, since mesoporous carbons have in general increased areas compared to silicas, there are indeed significant advantages in using the former as drug carriers at least in terms of loading capacities. 


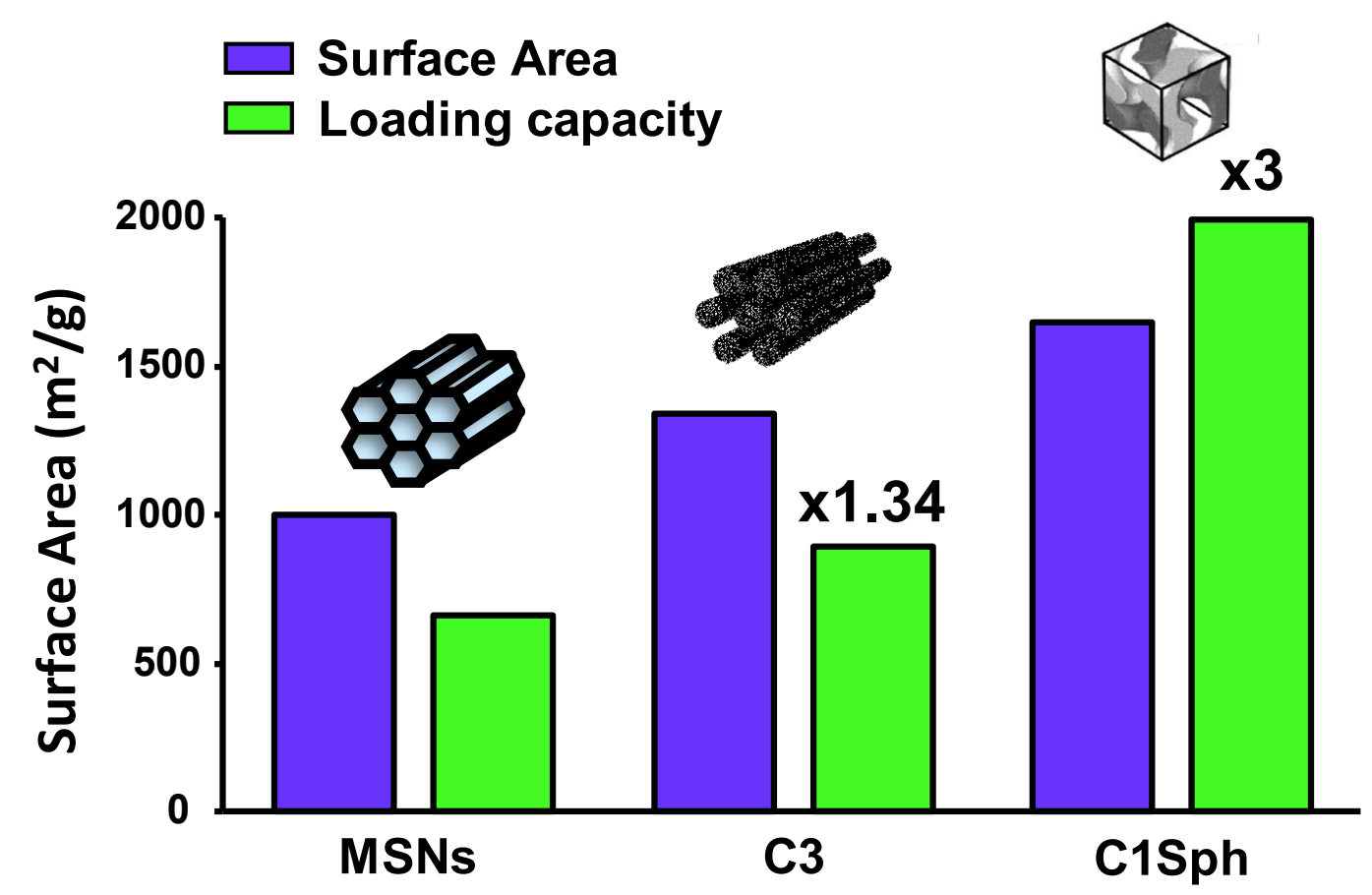

Figure 2. Surface area and loading capacity of mesoporous silica (MSNs) and carbon (C3, C1Sph) matrices. The loading capacity is referred to that of MSNs. Both carbon matrices can accommodate higher amount of dye. In particular, C1Sph can load up to 3 times the molecules adsorbed in MSNs.

Self-immolative polymers. Having confirmed that greater surface areas led to greater loading capacities, the next step was to synthesize the $\mathrm{pH}$-responsive coating. The monomer and the trigger (compounds 1 and 2, respectively) were produced from 
commercially available 4-aminobenzyl alcohol, using phenyl chloroformate for the former and $\mathrm{BOC}$ anhydride for the latter, which provided the $\mathrm{pH}$-sensitivity to the polymeric chain.

The self-immolative polymer (compound 3 ) was produced from compounds 1 and 2 in the presence of a tin catalyst, yielding polymers composed of $c a .20$ units $(3300 \mathrm{~g} / \mathrm{mol})$.

Properties of polymer-coated mesoporous carbons. The surface properties of the asproduced carbon carriers were evaluated through XPS analyses to unravel the chemical groups available on the surface and develop an adequate grafting protocol. The spectra (Figure S6), indicated the presence of hydroxyl, carboxyl and epoxy groups. In consequence, the synthesis of C3-SIP and C1Sph-SIP was accomplished by addition of the SIP to the carbon nanoparticles to form stable ether groups (Scheme S2).

The SIP-coated mesoporous carbon particles were characterized using TEM, $\mathrm{N}_{2}$ adsorption-desorption at $77 \mathrm{~K}$, TGA, Dynamic Light Scattering (DLS) and XPS. TEM micrographs (Figure S7) confirmed the successful particle coating, while Table 1 shows the modifications in the textural properties and the organic content of the carbon carriers before and after the functionalization (see also Figures S8 to S11). DLS measurements on pristine and coated particles demonstrated that the polymeric coating prevents 
agglomeration of the particles and thus improves their colloidal stability, making them more suitable for biological applications (Figure S12). In addition, the SIP-coated particles were subjected to harsh conditions $\left(75^{\circ} \mathrm{C}, 4\right.$ days) and then analyzed by DLS measurements, demonstrating that the coated particles remained unaffected and assuring their integrity under physiological conditions (Figure S13).

Table 1. Comparison of the textural properties and the organic matter content of $\mathrm{C} 3, \mathrm{C} 3-$ SIP, C1Sph and C1Sph-SIP.

\begin{tabular}{lllllll}
\hline & $\begin{array}{l}\mathrm{S}_{\mathrm{BET}} \\
\left(\mathrm{m}^{2} / \mathrm{g}\right)\end{array}$ & TPV $\left(\mathrm{cm}^{3} / \mathrm{g}\right)$ & $\begin{array}{l}\mathrm{V}_{\text {micro }} \\
\left(\mathrm{cm}^{3} / \mathrm{g}\right)\end{array}$ & $\begin{array}{l}\mathrm{V}_{\text {meso }} \\
\left(\mathrm{cm}^{3} / \mathrm{g}\right)\end{array}$ & $\begin{array}{l}\text { Pore width } \\
(\mathrm{nm})\end{array}$ & $\begin{array}{l}\text { \% Weight } \\
\text { loss }\end{array}$ \\
\hline C3 & 1340 & 1.4 & 0.1 & 1.3 & 4.5 & - \\
C3-SIP & 620 & 0.6 & 0.0 & 0.6 & 4.1 & $14.8^{\mathrm{a}}$ \\
C1Sph & 1650 & 1.2 & 0.2 & 1.0 & 3.2 & - \\
C1Sph & 560 & 0.4 & 0.1 & 0.3 & 3.0 & $14.9^{\mathrm{a}}$ \\
-SIP & & & & & & \\
\hline
\end{tabular}

a Weight loss compared to the non-modified carbon carriers.

TGA showed a difference in weight loss of $c a .15 \%$ within the range $150-450^{\circ} \mathrm{C}$ for both SIP-coated carbons when compared with the bare particles, due to the presence of organic matter on the coated materials (Figure S8 for C1Sph-SIP and Figure S9 for C3- 
SIP). The successful SIP coating was also confirmed by comparison of the $\mathrm{N}_{2}$ adsorption/desorption isotherms at $77 \mathrm{~K}$ measured for C1Sph-SIP (Figure S10) and C3SIP (Figure S11) against those of the pristine carbons, revealing a great decrease of the BET area (ca. $65 \%$ for the C1Sph-SIP and ca. $55 \%$ for C3-SIP) and pore volume after SIP coating, as shown in Table 1. Furthermore, based on the $\mathrm{N}_{2}$ adsorption isotherms (external surface) and the TGA results (SIP loading), grafting densities of ca. 0.4-0.5 $\mu \mathrm{mol} / \mathrm{m}^{2}$ were deduced for both samples (see SI).

The hybrid materials were also subjected to XPS analysis. The obtained spectra (Figure 3) show some differences when compared to those of the bare particles (Figure S6), indicating their successful modification (Table S1 for detailed analysis). The amount of CC/C-H peaks for the SIP-coated carbons appears reduced while the signals that may pertain to C$\mathrm{N}$ bonds (amines, $286.0 \mathrm{eV} ;{ }^{45-51}$ amides, $288.7 \mathrm{eV} ;{ }^{49}$ carbamates, $290.1 \mathrm{eV}^{45,49}$ ), have in general increased. Nevertheless, the most significant evidence of the interaction of the polymer with the carbon surface is the presence of the N1s photoelectron peak $(400.5 \mathrm{eV})^{45-47,50}$ for both SIP-coated carbon materials (Figures $3 \mathrm{~A}$ and $3 \mathrm{~B}$, insets), which is ascribed to the carbamate groups present throughout the self-immolative polyurethane, indicating the successful grafting of the polymer on the surface of both $\mathrm{C} 3$ and $\mathrm{C} 1 \mathrm{Sph}$ carbon materials. 


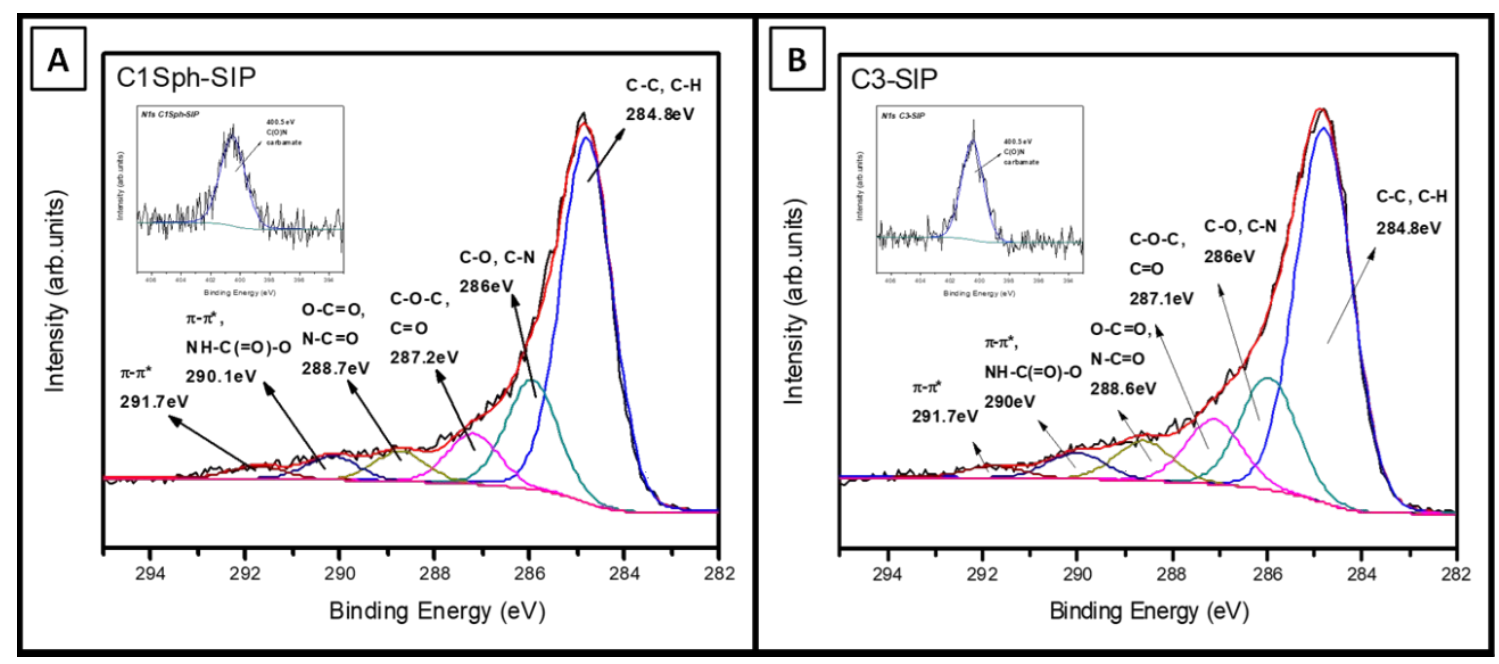

Figure 3. XPS analyses of the SIP-coated carbons. A) C1Sph-SIP. B) C3-SIP. The plots, that show the expected signals for a carbon framework, exhibit signals associated to the carbamates present in the polymers, confirming the interaction of the polymer with the surface.

Release experiments from SIP-coated mesoporous carbon particles. Several release experiments were performed to evaluate the $\mathrm{pH}$-responsiveness of the hybrid mesoporous carbons, using a model fluorescent ruthenium complex as cargo. The use of nontoxic dyes as model payload to study the smart behavior of mesoporous nanomatrices is well-stablished and allows the evaluation of their stimuli-responsiveness without using cytotoxic compounds, thereby reducing potential experimental-associated 
toxicity. ${ }^{52-56}$ To mimic the physiological conditions, the Ru-loaded and SIP-coated nanocarriers were subjected to orbital stirring at $37^{\circ} \mathrm{C}$, using two $\mathrm{pH}$ values ( 5 and 7.4 ), corresponding to the lysosomal environment and the physiological body fluids, respectively. (Figure 4).

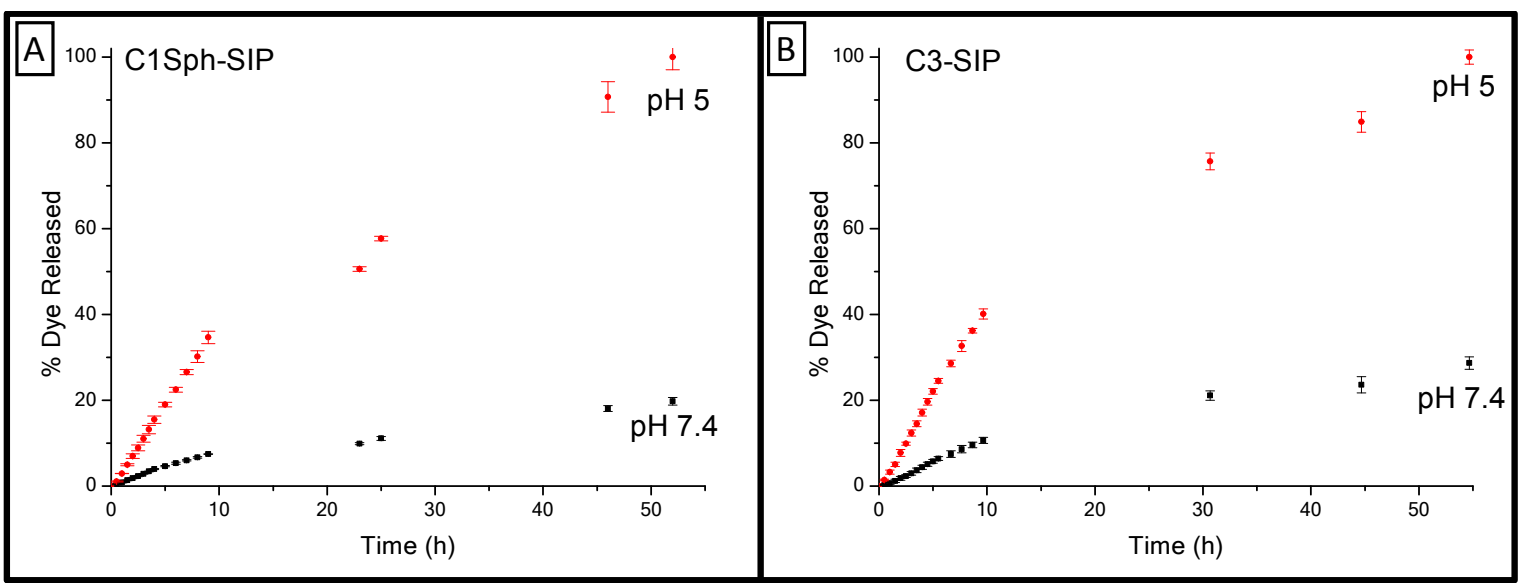

Figure 4. Release experiments. A) C1Sph-SIP. B) C3-SIP. At neutral pH the polymer remains on the surface, inhibiting the drug release. Nevertheless, the polymer selfimmolates at acid $\mathrm{pH}$, leading the opening of the pores and subsequent release. Error bars indicate standard deviation ( $\mathrm{n}=3$ per condition).

Both release kinetics clearly show that the polymer is capable of hampering the dye release at $\mathrm{pH} 7.4$, which would assure the biosafety of the carriers in vivo. However, at $\mathrm{pH} 5$ the polymer disassembles and the dye can be easily released from both mesoporous 
carbon particles in a sustained fashion. In particular, for C1Sph-SIP (Figure 4A) even after 50 hours of experiment only $20 \%$ of the dye was released at $\mathrm{pH} 7.4$. Unlike the samples at physiological $\mathrm{pH}$, those at $\mathrm{pH} 5$ a five-fold release was measured. With regard to $\mathrm{C} 3-$ SIP (Figure 4B), $28 \%$ of dye was released after 50 hours at $\mathrm{pH} 7.4$, while a $c a$. four-fold release was observed at $\mathrm{pH}$ 5. Compared to C1Sph-SIP, more dye was released at physiological $\mathrm{pH}$ for C3-SIP, which can be connected with the larger pore size of $\mathrm{C} 3$ carbon but also with its more open pore architecture compared to C1Sph (in CMK-3 the connectivity is infinite since all the pores are directly connected with the external space; on the contrary in CMK-1 there is a more confined worm like pore system).

Cytotoxicity studies. The in vitro biocompatibility and cytotoxicity (measured by Alamar Blue) of the polymer-grafted carriers was evaluated using human osteosarcoma (HOS) cells at 24 and 48 hours for three particles concentrations $(25,50$ and $100 \mu \mathrm{g} / \mathrm{mL})$. For this purpose, three different set-ups were used for each nanocarrier. The biocompatibility was investigated using unloaded polymer-grafted carbons (denoted as X-SIP, X indicating either $\mathrm{C} 3$ or $\mathrm{C} 1 \mathrm{Sph})$. To evaluate their cytotoxic effect, both carbon materials were loaded with a widely used chemotherapeutic drug, namely doxorubicin, and then 
coated with the polymeric layer (denoted as X-DOX-SIP). In addition, to confirm that the polyurethane actually undergoes self-immolation upon exposure to acid $\mathrm{pH}$ and, consequently, can effectively act as gatekeeper, an additional group of materials was prepared. For this purpose, both mesoporous carriers were loaded with DOX and then coated with an analogous polyurethane without the triggering moiety responsive to acid $\mathrm{pH}$ (denoted as X-NOBOC) (Figure 5). 


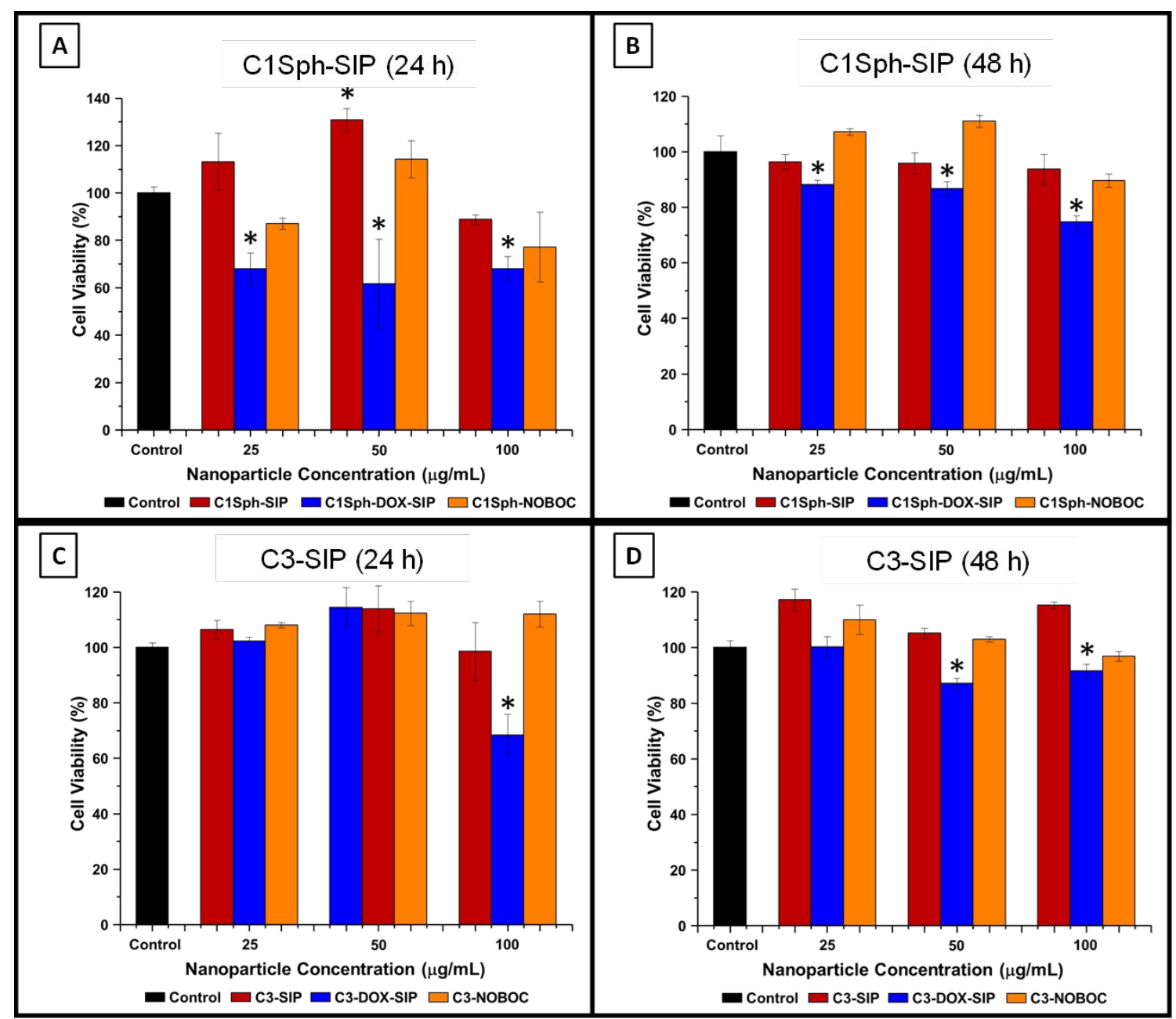

Figure 5. Cytotoxicity assay measured by Alamar Blue in HOS cells. A) 24 hours and B) 48 hours experiments of C1Sph-SIP, C1Sph-DOX-SIP and C1Sph-NOBOC. C) 24 hours and D) 48 hours experiments of C3-SIP, C3-DOX-SIP and C3-NOBOC. Data are mean \pm SEM of 3 independent experiments performed in duplicate. ${ }^{*} p<0.05 v s$. X-SIP and control. 
In both cases, the drug-free nanocarriers showed negligible cytotoxicity on the cells for all the studied concentrations and times. Interestingly, a significant increase of cell proliferation was observed for C1Sph-SIP when a concentration of $50 \mu \mathrm{g} / \mathrm{mL}$ was employed (Figure 5A). This behavior has also been observed for carbon nanotubes on different cell lines. ${ }^{57,58}$ When using C1Sph-DOX-SIP, the hybrid nanocarrier was capable of exerting cytotoxicity at 24 and 48 hours (Figures $5 \mathrm{~A}$ and $5 \mathrm{~B}$ ) for all concentrations, being higher at 24 hours. Nonetheless, for C3-SIP, only the highest concentration was capable of inducing significant reduction of the viability at 24 hours (Figure 5C). A plausible explanation for that would be that doxorubicin release from the particle is mediated by the disruption of $\pi-\pi$ interactions between the carbon matrix and the host molecules, being faster at the beginning. ${ }^{33}$ On this basis, the majority of cells would die within the first 24 hours. Finally, in both cases the control groups loaded with the drug and functionalized with a polymer without the $\mathrm{pH}$-responsive trigger (in orange) did not show inhibition of the cell viability. In other words, the presence of the triggering moiety responsive to acid $\mathrm{pH}$ is required for the self-immolation of the polyurethane and 
subsequent opening of the pore entrances and drug release to take place, thereby verifying in vitro the $\mathrm{pH}$-responsiveness of the polymer-coated carbons.

In general, the cytotoxic effect of C3-SIP is much lower than that observed for C1SphSIP. A plausible hypothesis would be that, generally speaking, small nanoparticles are internalized by cells more easily than those which are bigger and as such, a smaller amount of C3-SIP particles is expected to be present inside the cells. In consequence, less amount of drug would be released inside the cells, leading to a reduced effect on their viability. In this sense, only the $100 \mu \mathrm{g} / \mathrm{mL}$ C3-SIP group was found to exert cell inhibition at 24 hours, while the particles at a concentration of $50 \mu \mathrm{g} / \mathrm{mL}$ induced the first cytotoxic effect at 48 hours. Apart from the size, the higher loading capacity of C1sph compared to that of $\mathrm{C} 3$ might also be an explanation for the greater cytotoxic effect of the SIP-coated C1Sph carbons.

In vivo proof of concept study: Preliminary in vial short-term pH triggering. These promising results, both in vitro and in vial, called for further in vivo proof of concept validation of the here designed systems. C1Sph-SIP was selected for the in vivo experiments due to their outstanding textural properties, release profile and cytotoxic 


\begin{abstract}
effects on cells. The experiments were carried out in mice. The fluorescent Ru was chosen as a model drug in order to allow fluorescence-based detection of payload release from the carrier, both in vial and in vivo.
\end{abstract}

Before performing the in vivo experiments, the short-term $\mathrm{pH}$-responsiveness of C1Sph-SIP loaded with Ru was analyzed in vial (Figure 6), showing that only those materials incubated at acid $\mathrm{pH}$, for either 30 minutes or 24 hours, led to significant payload release. This result indicates that 0.5 hours is enough time to trigger the self-immolation of the gatekeeper and initiate the payload release. In consequence, the SIP-coated mesoporous carbon nanocarrier should be unaffected by any potential in vivo homeostasis.

After this test, those materials were immersed in a solution at physiological $\mathrm{pH}(\mathrm{pH} 7.4)$ for further 24 hours, observing that only the materials that had been previously treated with the acid solution kept releasing the payload. On the other hand, the particles initially soaked at physiological $\mathrm{pH}$ kept showing residual release, unquestionably demonstrating the $\mathrm{pH}$-responsiveness of the nanocarrier. 


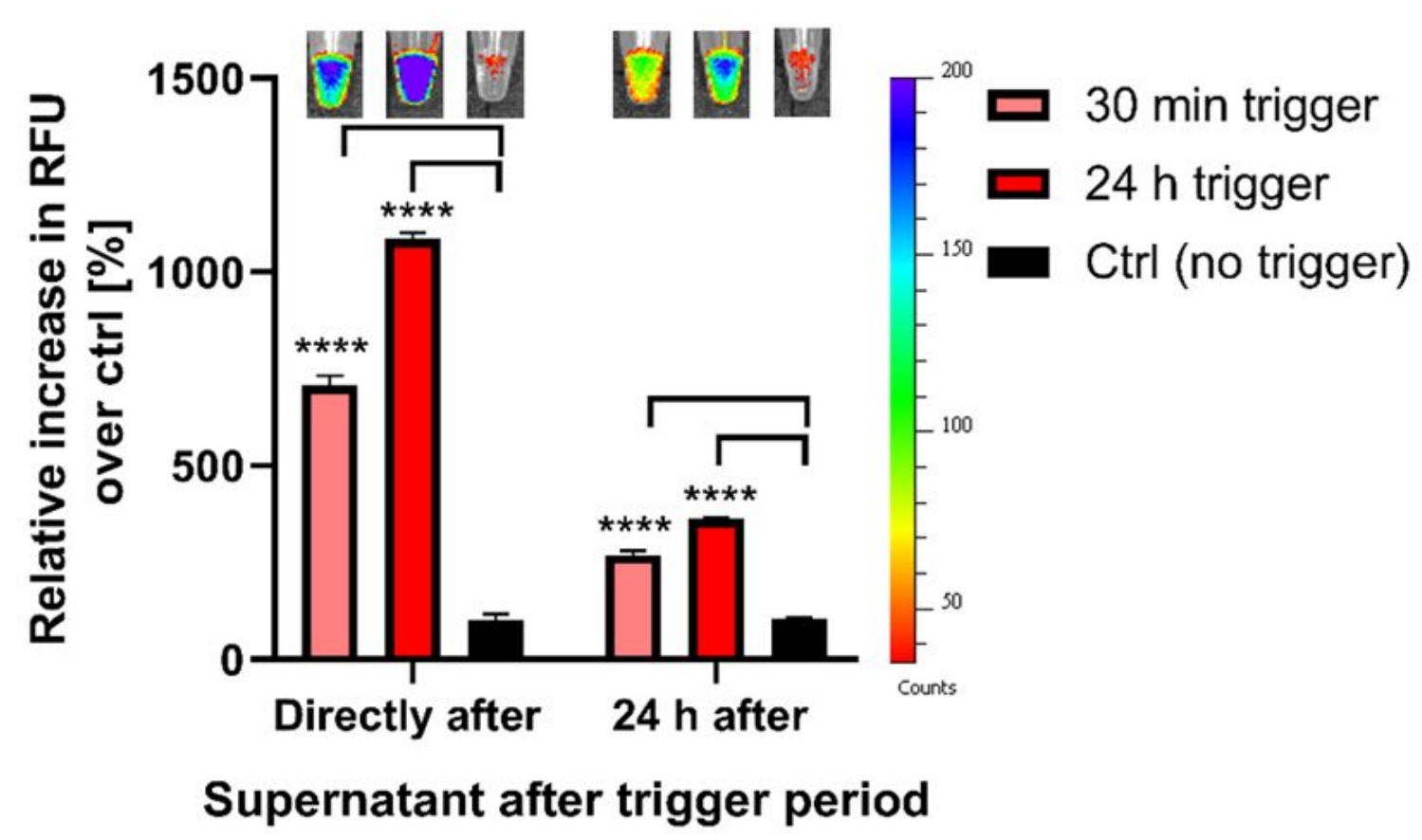

Figure 6. In vial release experiment of C1Sph-SIP loaded with $\mathrm{Ru}$. The materials were immersed in acid ( $\mathrm{pH} \mathrm{4,} \mathrm{red)} \mathrm{or} \mathrm{physiological} \mathrm{solutions} \mathrm{(} \mathrm{pH} 7.4$, black) and the supernatants were analyzed by the IVIS ${ }^{\circledR}$ apparatus. After that, all groups were soaked in a solution at physiological $\mathrm{pH}$ and analyzed again 24 hours later. This test confirms that just the groups that had been previously treated with the acid environment are capable of inducing significant and continuous payload release. Top images constitute representative IVIS $₫$ images for each condition. Data are mean \pm standard deviation $\left(n=3 ; n=2\right.$ for $24 h$ trigger). Statistics: unpaired, two-tailed t-test, $p^{*} \leq 0.05$, conditions always referred to control per time point. 


\section{In vivo proof of concept study: Integrity of C1Sph-SIP and biocompatibility. Having}

confirmed in vial that a short exposure to acid $\mathrm{pH}$ can trigger the payload release, the next objective was to find out in vivo if (1) the pores remain closed at physiological pH and (2) the materials induce in vivo reactions towards the particles.

To detect potential Ru release from the material $(1)$, the mice $(n=3)$ were administered the hybrid particles in a physiological solution with $\mathrm{pH} 7.4$ via subcutaneous (s.c.) injection. After that, mice were visualized along the longitudinal axis using the IVIS $®$ before and after administering the particles. Animals were also imaged at different time points (24, 48 and 96 hours) after the administration the SIP-coated mesoporous carbon (Figure 7A). Of note, the Ru-loaded C1Sph-SIP carbons emitted imperceptible fluorescence signal, meaning that the SIP remained intact and, therefore, closing the pores. The injected material itself cannot be visualized in the IVIS ${ }^{\circledR}$, only the release of the fluorophore can be tracked. Overall, only little fluorophore release was detected, indicating that there was no substantial degradation of the SIP polymer in vivo under physiological conditions and in the absence of a $\mathrm{pH}$-trigger. 

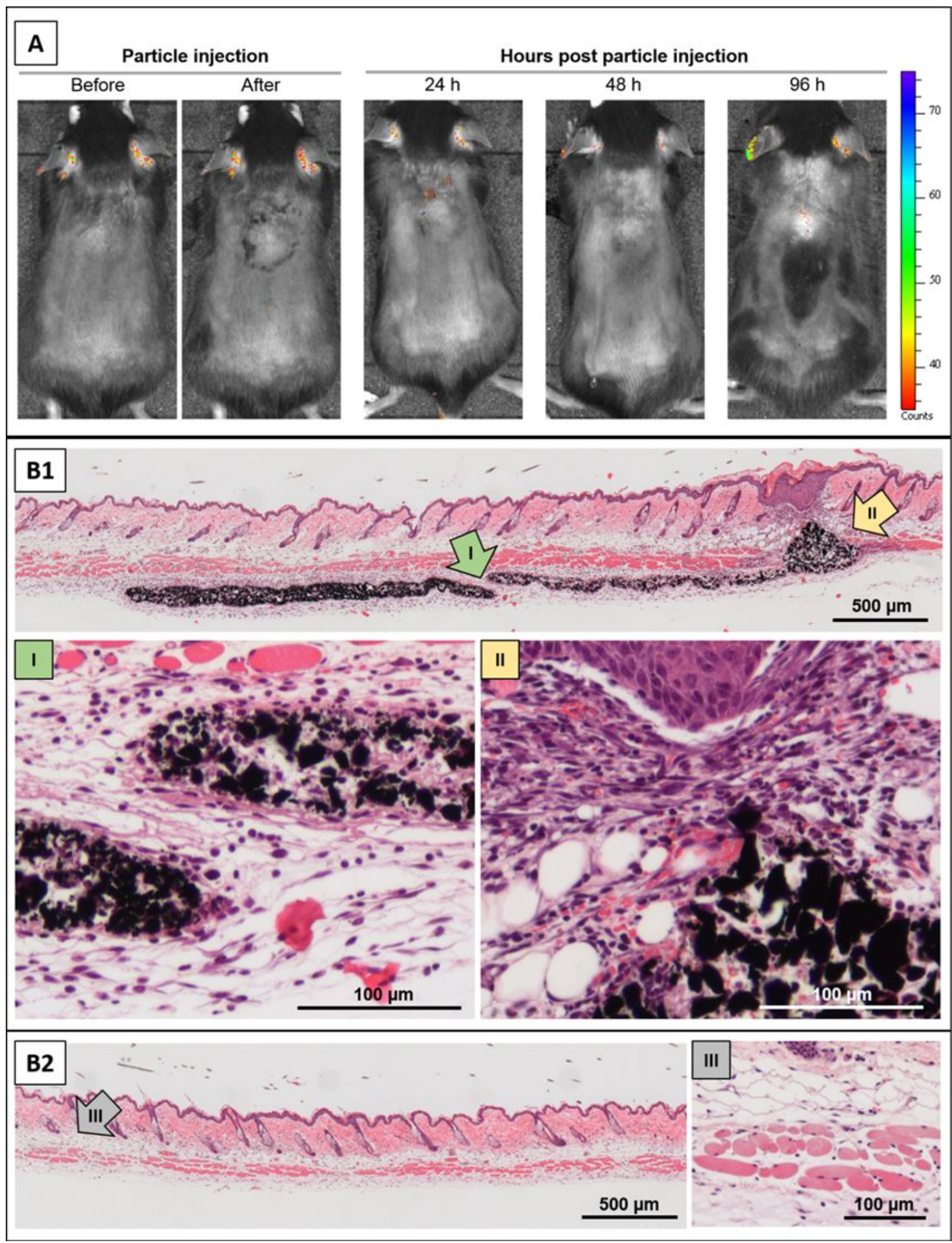

Figure 7. Behavior of Ru-loaded C1Sph-SIP particles in the absence of an exogenous $\mathrm{pH}$

trigger after subcutaneous injection into mice. A) Imaging of the dorsal site of the animals 
along the longitudinal axis using the $\mathrm{IVIS}^{\circledR}$ before and directly post injection of the Ruloaded C1Sph-SIP particles, as well as 24,48 and $96 \mathrm{~h}$ post injection (images from left to right). The following filter set for excitation/ emission was used: $465 \mathrm{~nm} /$ Cy5.5. Images of one animal are shown as examples. No exogenous $\mathrm{pH}$-trigger was applied. B) H\&Estained sections of paraffin-embedded skin tissue with (B1) and without (B2) injected C1sph-SIP (black) 96 hours post injection. Nuclei stained in purple, cytoplasm and connective tissue in light pink, muscle tissue in dark pink. A and B comprise overview mosaic images, magnification 10x; the numbered and colored arrows point to the sites that are presented in higher magnification (40x) in a separate image. B1.I (green): moderate capsule formed near the administered mesoporous carbons and only low presence of immune cells can be observed; B1.II (yellow): substantial immune reaction against the wounded skin area due to tissue puncture during injection; B2.III (grey): control healthy skin tissue with dermis, subcutaneous adipose and muscle as well as loose connective tissue. (Representative images are shown). 
To study the general biocompatibility (2), the mice were visually analyzed each day for irritations of the site of the injection, general aspect and behavior. Moreover, the weight was monitored at all imaging time points. No adverse reactions due to the presence of the materials were observed for any of the mice. The mice were imaged after 96 hours and subsequently sacrificed. The injection site was explanted and further prepared for histological analysis. Figure 7B entails representative H\&E stained images of skin and subcutaneous tissue with injected particles (Figure 7B1) as well as non-injected skin tissue as control (Figure 7B2). The organism reacted to the injected materials by forming a moderate capsule around the mesoporous nanocarriers and low presence of immune cells in the injection site (Figure 7B1.I), compared to injection-free skin (Figure 7B2.III). Figure 7B1.II shows the injection site where the injury from the needle results in a more pronounced immune reaction. The comparison of the immune reaction towards the skin wound (Figure 7B1.II) with the reaction towards the particles (Figure 7B1.I) shows the only mild foreign-body response to the material.

In vivo proof of concept study: Fluorophore release in response to exogenous $\mathrm{pH}-$ triggering. Having confirmed the responsiveness of the material to short-term $\mathrm{pH}-$ 
triggering in vial, the only minor reaction of the organism to the particles and the integrity of the hybrid system over 96 hours in vivo, it was investigated whether the self-immolation of the polyurethane could be initiated in an in vivo set up upon application of an exogenous acid $\mathrm{pH}$ trigger. A solution at $\mathrm{pH} 4$ was used to slow down $\mathrm{pH}$ homeostasis that might interfere with the $\mathrm{pH}$-sensitive particles. As a control, a physiological $\mathrm{pH}$ trigger was included $(\mathrm{pH} 7.4)$. For this, $\mathrm{pH}$-responsiveness was monitored with the IVIS ${ }^{\circledR}$; the trigger was applied via injections of $\mathrm{pH}$ solution (multiple cycles of injection of $\mathrm{pH}$ solution followed by 10 min incubation time adding up to at least 30 min of triggering) into the injection site. The animals were imaged at different time points (before as well as during and after applying the trigger). The mice were also imaged at 24 and 72 hours after the triggering period. In a proof of concept approach, fluorophore release in response to triggering with low $\mathrm{pH}(\mathrm{pH} 4, \mathrm{n}=4)$ was detected during the trigger period, while no

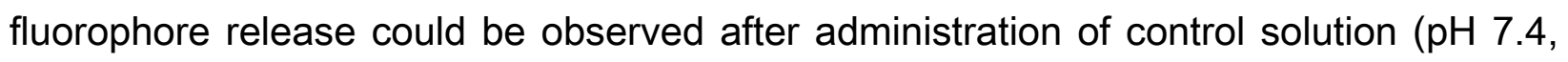
$\mathrm{n}=2$ ) (Figure 8). 


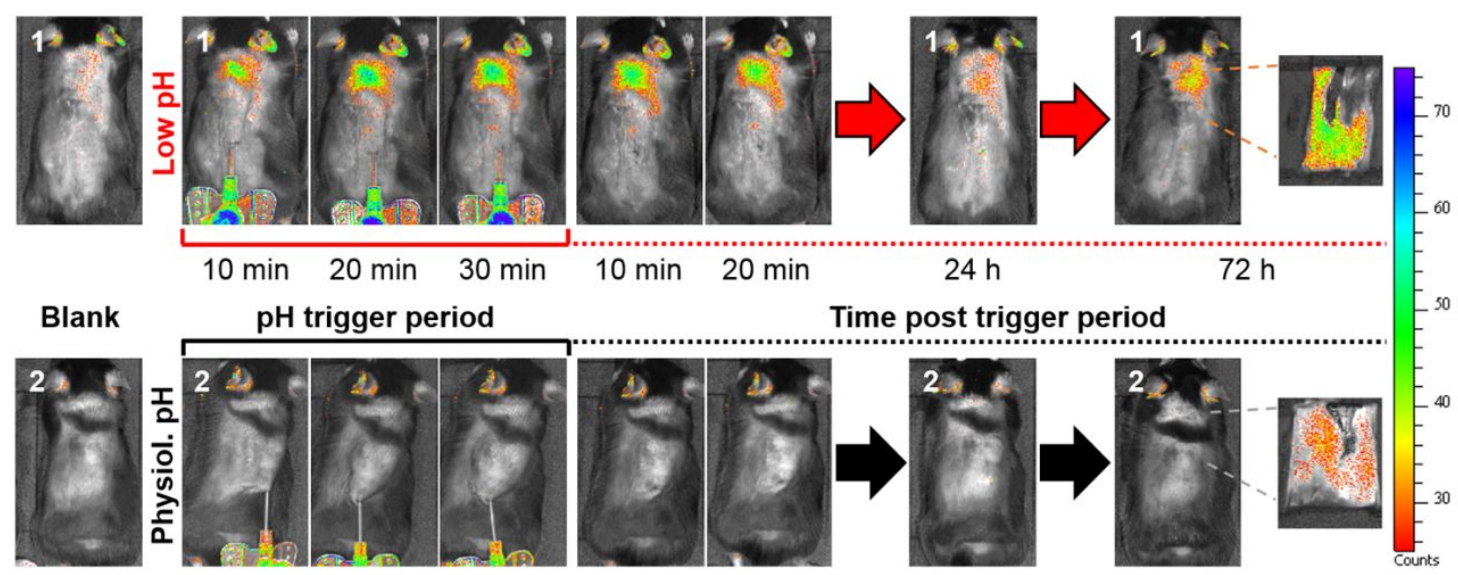

Figure 8. Monitoring of Ru release from C1Sph-SIP particles in the presence of an exogenous $\mathrm{pH}$ trigger after subcutaneous injection into mice. Longitudinal IVIS ${ }^{\circledR}$ imaging over $72 \mathrm{~h}$, shown for two animals $(1,2)$ that received particles and $\mathrm{pH}$ trigger $(1=\mathrm{pH} 4$ (top); $2=\mathrm{pH} 7.4$ (bottom)). $\mathrm{pH}$ triggering was performed via multiple injections using a dwelling cannula over 30 min and imaged during the trigger period and over $20 \mathrm{~min}, 24$ and $72 \mathrm{~h}$ post triggering. The animals were sacrificed, and the areas where the injections took place extracted, inverted and visualized again. The following filter set for excitation/ emission was used: $465 \mathrm{~nm} /$ Cy5.5. Representative images for each condition are shown.

After the initial triggering, the fluorescence of the Ru payload could be continuously detected during the whole experiment (72 hours) for the group that received the solution 
at $\mathrm{pH} 4$ whereas just a small amount of fluorescence was seen for the mice that received the solution at $\mathrm{pH}$ 7.4. The mice were euthanized after 72 hours, and the place where the injections took place was collected, inverted and visualized, showing strong fluorescent signal for $\mathrm{pH} 4$ triggered hybrid systems and only minor signals for the $\mathrm{pH} 7.4$ treated animals. This indicates a successful SIP degradation in response to administration of exogenous acidic $\mathrm{pH}$-triggering over a short time period and, thus, validated the $\mathrm{pH}-$ responsiveness of the hybrid system in an in vivo and more complex setting.

\section{CONCLUSIONS}

In this work two types of mesoporous carbon particles with different morphology and pore structure have been successfully synthesized and functionalized with a $\mathrm{pH}-$ responsive polymer. The initial hypothesis of the higher loading capacity of the carbon materials, compared to the well-studied mesoporous silica nanoparticles, has been verified through thermogravimetric analysis, showing up to 3 times the loading capacity 
of conventional mesoporous silica. The acid-responsive nature of the carriers has been in vial, in vitro and in vivo at physiological and lysosomal $\mathrm{pH}$, demonstrating that the drug release would only take place inside the target cell. Moreover, the cellular experiments on HOS cells have demonstrated that only the doxorubicin-loaded hybrid materials are able to induce significant decrease in the cell viability, especially when using the C1SphSIP materials. Furthermore, the integrity C1Sph-SIP, which presented the highest loading capacity, the best release profile and the highest cytotoxicity effect on tumoral cells, has been confirmed over 96 hours in vivo and no adverse reactions were observed during the investigated time period, showing the high biocompatibility of the material. Additionally, the rapid $\mathrm{pH}$-responsiveness of the hybrid system to short-term triggering with acidic $\mathrm{pH}$ was successfully demonstrated in vivo with a continuous payload release over a 72-hour period. In consequence, the obtained results demonstrate the suitability of the studied carbon materials to be considered as highly efficient and biocompatible smart drug delivery nanocarriers of $e . g$. anticancer active agents.

MATERIALS AND METHODS 
Materials. Tetraethyl orthosilicate (TEOS); Pluronic P123 and F127; Cetyltrimethylammonium bromide (CTAB); Phenyl chloroformate; 4-Aminobenzyl alcohol;

Dibutyltin dilaurate (DBTL); N,N-Diisopropylethylamine (DIPEA); $\quad$ Tris(2,2'bipyridyl)dichlororuthenium(II) hexahydrate $(\mathrm{Ru})$ and Di-tert-butyl dicarbonate were purchased from Sigma-Aldrich Inc. Solvents (Dimethyl sulfoxide (DMSO); Tetrahydrofuran (THF); Dichloromethane (DCM), N,N-Dimethylformamide (DMF); Ethanol; Heptane; Ethyl Acetate; Methanol) were also purchased from Sigma-Aldrich Inc.

Synthesis of CMK-3 type ordered mesoporous carbon nanoparticles. CMK-3 type ordered mesoporous carbons (denoted as C3) were produced through a nanocasting procedure, 44,59 employing SBA-15 mesoporous silica as template. Sucrose was employed as carbon precursor. The silica template was synthesized following previously reported methods, ${ }^{60-62}$ using TEOS as silica source and the triblock copolymer Pluronic P123 as surfactant templating agent. The following composition was employed: TEOS (2 g): P123 (1 g) in $38 \mathrm{~mL} \mathrm{HCl} 1.6 \mathrm{M})$. The mixture was placed in an autoclave at $35^{\circ} \mathrm{C}$ for $20 \mathrm{~h}$ and then aged at $90^{\circ} \mathrm{C}$ for 24 hours, drying and finally calcination at $550^{\circ} \mathrm{C}$ in air to remove the P123 soft template. The calcined SBA-15 was impregnated twice with $5 \mathrm{~mL}$ 
aqueous solution containing $1.25 \mathrm{~g}$ (first impregnation) and $0.8 \mathrm{~g}$ (second impregnation)

of sucrose per gram of silica and minute amounts of sulfuric acid (95-97\%) as catalyst.

After each impregnation step the mixture was thermopolymerized at $100^{\circ} \mathrm{C}(6 \mathrm{~h})$ and $160^{\circ} \mathrm{C}(6 \mathrm{~h})$. The final carbon replica was obtained by carbonization of the composite material at $900^{\circ} \mathrm{C}$ (ramp rate $\left.10^{\circ} \mathrm{C} / \mathrm{min}\right)$ for $2 \mathrm{~h}$ under $\mathrm{N}_{2}$ flow $(80 \mathrm{~cm} / \mathrm{min})$, followed by cooling to room temperature and dissolution of the silica framework using $48 \%$ hydrofluoric acid solution at room temperature.

Synthesis of CMK-1 type ordered mesoporous carbon nanospheres. A similar procedure was also adopted for the preparation of CMK-1 type mesoporous carbon with spherical morphology (denoted as C1Sph). In this case, MCM-48 ordered mesoporous silica spheres were employed as starting hard template, and were synthesized according to the Stöber method with some modifications, ${ }^{63}$ employing a mixture of surfactants in a solution containing $\mathrm{H}_{2} \mathrm{O}, \mathrm{NH}_{3}$ and $\mathrm{EtOH}$. The reaction was carried out at room temperature and under static conditions. In brief, TEOS was used as silica source, CTAB (cationic surfactant) was employed as the templating agent and Pluronic F127 (nonionic surfactant) as suppressant of the silica particles grain growth. ${ }^{18}$ The carbon replica was 
obtained following the same procedure as with $\mathrm{C} 3$, i.e., infiltration (twice) of the calcined MCM-48 silica "mold" with acidic sucrose solution, thermopolymerization, carbonization at $900^{\circ} \mathrm{C}$ under $\mathrm{N}_{2}$ flow and silica removal with $\mathrm{HF}$.

Synthesis of mesoporous silica nanoparticles. Apart from the C3 and C1Sph carbons, mesoporous silica nanoparticles (denoted hereafter as MSNs) were also synthesized (to serve as control) following a modified Stöber method reported elsewhere. ${ }^{64}$ Briefly, $1 \mathrm{~g}$ (2.74 mmol) of CTAB was dissolved in a flask containing $480 \mathrm{~mL}$ of $\mathrm{H}_{2} \mathrm{O}$ and $3.5 \mathrm{~mL}$ of $\mathrm{NaOH}$ at $80^{\circ} \mathrm{C}$. After that, $5 \mathrm{~mL}(22.39 \mathrm{mmol})$ of TEOS was added dropwise $(0.25 \mathrm{~mL} / \mathrm{min})$ and the whole reaction mixture was kept for $2 \mathrm{~h}$ at $80^{\circ} \mathrm{C}$ with stirring. Afterwards, the nanoparticles were centrifuged and washed (water, ethanol). Finally, the template was removed refluxing the as-produced nanoparticles three times in $500 \mathrm{~mL}$ of an ethanolic solution $(95 \%)$ of $\mathrm{NH}_{4} \mathrm{NO}_{3}(10 \mathrm{mg} / \mathrm{mL})$.

Analytical methods. Details on ${ }^{1} \mathrm{H}-\mathrm{NMR}, \mathrm{SAXS}, \mathrm{N}_{2}$ adsorption-desorption (77K), XPS, TGA, DLS, SEM and TEM measurements are given as Supporting Information.

Determination of the loading capacity. Portions of $15 \mathrm{mg}$ of each of the three nanoparticles (MSNs, C3 and C1Sph) were soaked in $2 \mathrm{~mL}$ of ethanol containing $34 \mathrm{mg}$ 
(0.04 mmol) of $\mathrm{Ru}$ overnight. The impregnated materials were filtered, washed with ethanol $(40 \mathrm{~mL})$ and vacuum-dried. The loading capacity was evaluated through the thermogravimetric analysis of all Ru-loaded materials, in comparison with each unloaded counterpart. The percentage of weight loss due to the cargo was calculated between $250^{\circ} \mathrm{C}$ and $350^{\circ} \mathrm{C}$.

\section{Synthesis of phenyl (4-hydroxymethyl)phenyl)carbamate (Compound 1). For the} synthesis of compound 1, a slightly modified reported method was followed. ${ }^{65}$ In brief, 1.5 $\mathrm{g}$ (12 mmol) of 4-aminobenzyl alcohol was dissolved in $60 \mathrm{~mL}$ of a mixture of THF/saturated aqueous sodium bicarbonate/water (2:2:1). After that $1.7 \mathrm{~mL}(12 \mathrm{mmol})$ of phenyl chloroformate was added dropwise and the reaction was stirred at room temperature until it was completed (controlled by TLC chromatography). Then, compound 1 was extracted in ethyl acetate and washed with sodium bicarbonate. Afterwards, the organic phase was dried using sodium sulfate as desiccant agent. Finally, the solvent was removed and the crude was recrystallized in chloroform to yield compound 1 , which was characterized by proton nuclear magnetic resonance ( $\left.{ }^{1} \mathrm{H}-\mathrm{NMR}\right)$. 
Synthesis of tert-butyl (4-hydroxymethyl)phenyl)carbamate (Compound 2). For the synthesis of compound 2 , a slightly modified reported method was employed. ${ }^{66}$ In brief, 1 $\mathrm{g}(8.12 \mathrm{mmol})$ of 4-aminobenzyl alcohol was dissolved in $14 \mathrm{~mL}$ of DCM. After that, 1.94 $\mathrm{g}(8.75 \mathrm{mmol})$ of di-tert-butyl dicarbonate in $3 \mathrm{~mL}$ of DCM was added and the mixture was stirred overnight at room temperature. Then, the solvent was removed and the crude was purified on a silica column (ethyl acetate/heptane, 1:1), yielding compound 2 , which was characterized by ${ }^{1} \mathrm{H}-\mathrm{NMR}$.

Synthesis of poly(phenyl (4-hydroxymethyl)phenyl)carbamate) (Compound 3). $1 \mathrm{~g} \mathrm{(4.12}$ $\mathrm{mmol})$ of compound 1 were dissolved in $2.1 \mathrm{~mL}$ of dry DMSO. Then, $73 \mu \mathrm{L}(3 \% \mathrm{~mol})$ of DBTL were added and the reaction was stirred for $2 \mathrm{~h}$ at $85^{\circ} \mathrm{C}$. After that, the reaction was cooled down to $40^{\circ} \mathrm{C}$ and $223 \mathrm{mg}(1 \mathrm{mmol})$ of compound 2 in $0.5 \mathrm{~mL}$ of dry DMSO were added slowly. Then, the mixture was heated again at $85^{\circ} \mathrm{C}$ and stirred for 2 hours. Finally, compound 3, which was isolated by precipitation of the reaction in cold $\mathrm{MeOH}$ and subsequent centrifugation, was dried and characterized using ${ }^{1} \mathrm{H}-\mathrm{NMR}$.

Synthesis of self-immolative polymer-coated carbon nanoparticles. $30 \mathrm{mg}$ of either C1Sph or C3 nanoparticles were dispersed in $3 \mathrm{~mL}$ of dry DMF. In a different vial, 300 
$\mathrm{mg}(0.09 \mathrm{mmol})$ of compound 3 and $31 \mu \mathrm{L}(0.17 \mathrm{mmol})$ of dry DIPEA were dissolved in 2 $\mathrm{mL}$ of dry DMF. The mixture was stirred for 30 minutes at room temperature. Then, the latter solution was added to nanoparticles dispersion and temperature was set at $80^{\circ} \mathrm{C}$ for 24h. Finally, the newly formed hybrid materials (denoted as C1Sph-SIP and C3-SIP, respectively) were centrifuged, washed (DMF, water and ethanol) and dried. The hybrids were characterized by means of TGA, Z-potential, $\mathrm{N}_{2}$ adsorption, XPS and TEM.

Release experiments from Ru-loaded polymer-coated carbon nanoparticles. The carbons were loaded with a $\mathrm{Ru}$ dye before the SIP coating to evaluate the $\mathrm{pH}$ responsiveness of the hybrid materials. For that purpose, $30 \mathrm{mg}$ of either $\mathrm{C} 1 \mathrm{Sph}$ or $\mathrm{C} 3$ were dispersed in $3 \mathrm{~mL}$ of dry DMF containing $40 \mathrm{mg}$ ( $0.05 \mathrm{mmol})$ of $\mathrm{Ru}$, and the solutions were stirred for 24 hours at room temperature. Then, protocol described above for the grafting of the polymers was followed again.

The evaluation of the $\mathrm{pH}$-responsiveness of each hybrid nanocarrier was carried out via in vial release experiments. Two $\mathrm{pH}$ values were employed, namely $\mathrm{pH} 7.4(0.01 \mathrm{M}$ phosphate buffer) and $\mathrm{pH} 5$ (0.01 M acetate buffer). For this purpose, 2 batches of $10 \mathrm{mg}$ of the corresponding nanocarrier were prepared and dispersed in $1.8 \mathrm{~mL}$ of the 
corresponding buffer solution. Then, $0.5 \mathrm{~mL}$ of each suspension were placed on a Transwell ${ }^{\circledR}$ permeable support with a $0.4 \mu \mathrm{m}$ polycarbonate membrane $(\mathrm{n}=3$ for each condition). $1.5 \mathrm{~mL}$ of the corresponding medium were placed in the external well and the suspension was kept under continuous orbital shaking $\left(100 \mathrm{rpm}, 37^{\circ} \mathrm{C}\right)$. The solution from the external well was taken at every time point, fresh medium was added. The dye released was determined by fluorescence spectrometry.

Cytotoxicity studies. The mesoporous carbons were loaded with a cytotoxic drug to evaluate their effect on tumoral cells. For that purpose, $30 \mathrm{mg}$ of either $\mathrm{C} 3$ or $\mathrm{C} 1 \mathrm{Sph}$ were dispersed in $3 \mathrm{~mL}$ of dry DMF containing $42 \mathrm{mg}(0.07 \mathrm{mmol})$ of doxorubicin hydrochloride. Then, the mixture was soaked at room temperature for $24 \mathrm{~h}$. After that, the previously mentioned protocol for the grafting of the polymer was carried out again.

Cellular studies were carried out using HOS cells derived from a human osteosarcoma (CRL-1543; ATCC, Mannassas, VA). 20,000 HOS cells $\mathrm{cm}^{-2}$ were seeded into each well of 24-well plates (Corning, CULTEK, Madrid, Spain) at $37^{\circ} \mathrm{C}$ in a humidified atmosphere $\left(5 \% \mathrm{CO}_{2}\right)$ using Dulbecco's modified Eagle's medium (DMEM, Sigma Aldrich) containing $10 \%$ of heat-inactivated fetal bovine serum (FBS, Thermo Fisher Scientific) and $1 \%$ 
penicillin-streptomycin (Thermo Fisher Scientific). Then, the corresponding group of particles was placed in the corresponding wells and the whole system was incubated for 24 and 48h. Particle-free wells were also introduced and employed as controls.

Cell proliferation was determined by addition of Alamar Blue solution (Thermo Fisher Scientific) AbD at $10 \%(\mathrm{v} / \mathrm{v})$ to the cell culture at each time point (24 and $48 \mathrm{~h}$ ) of growth, following manufacturer's instructions. Fluorescence intensity was measured using excitation emission wavelengths of 570 and $600 \mathrm{~nm}$, respectively, in a Unicam UV-500 UV-visible spectrophotometer.

\section{In vial pre-testing of the pH-responsive nature of Ru-loaded C1Sph-SIP upon short-}

term $\mathrm{pH}$-triggering in preparation of in vivo application. The $\mathrm{pH}$-responsiveness of the hybrid system (C1Sph-SIP loaded with the fluorophore Ru as a model drug) to short-term $\mathrm{pH}$-triggering was investigated in via/by suspending the material in physiological solution (Sterofundin ${ }^{\circledR}$, B. Braun Melsungen, Germany) adjusted to a defined $\mathrm{pH}$ of 4 and 7.4 with $\mathrm{HCl}$ and $\mathrm{NaOH}$, respectively. Each group of particles was incubated for 30 min or 24 hours under either $\mathrm{pH} 4$ or $\mathrm{pH} 7.4$ conditions at $37^{\circ} \mathrm{C}$. After the trigger period, the particles were collected by centrifugation. The supernatant was collected, re-centrifuged $(2,000 \mathrm{~g}$, 
$5 \mathrm{~min}$ ) to remove remaining particles and imaged with the aid of the IVIS ${ }^{\circledR}$ Lumina (Caliper

LifeSciences, MA; ex/em filter: $465 \mathrm{~nm} /$ Cy5.5), as well as quantified in a plate reader

(Tecan Infinite Pro 200,ex / em 450/ 620 nm). The just centrifuged mesoporous carbons

were dispersed again in solution at $\mathrm{pH} 7.4$ and incubated at $37^{\circ} \mathrm{C}$ for further 24 hours.

Afterwards, the protocol (centrifugation, imaging of the supernatant and quantification)

was carried as described above.

In vivo proof of concept study. The study in mice was carried out in agreement with the

German Animal Welfare Act and received the approval of the local animal protection

authorities (LaGeSo; permit numbers: G 0293/17). The animals were kept under obligatory

hygiene standards as monitored according the FELASA standards. The animals had access to water and food ad libitum, were kept in gangs and randomly assigned to groups. The temperature was set to $20 \pm 2{ }^{\circ} \mathrm{C}$ and a light/dark period of $12 \mathrm{~h}$ was utilized.

The mice were anesthetized by inhalation of Isoflurane (2\%) mixed with oxygen during the procedures. Before the intervention, mice were administered $0.03 \mathrm{mg} / \mathrm{kg}$ of buprenorphine solution (Temgesic $®$, Schering-Plough, $N J)$ as analgesic via s.c. injection distant from the site of the material injection. Eyes were protected by eye ointment and animals were kept on a heating pad throughout the surgical intervention. 
The C1Sph-SIP hybrid systems loaded with Ru were administered to the C57BL/6 mice at a concentration of $3 \mathrm{mg} / 200 \mu \mathrm{l}$ s.c. dorsally close to the shoulder blades via injection through a $20 \mathrm{G}$ needle (Sterican ${ }^{\circledR}$, B. Braun-Melsungen, Germany) or dwelling canula (Vasofix ${ }^{\circledR}$, B.Braun-Melsungen, Germany), respectively. Prior to the injection, the fur in the dorsal region was clipped to avoid potential interferences of the mice hair with the IVIS $®$. To test the behavior of the Ru-loaded C1Sph-SIP hybrid systems in the absence of an exogenous $\mathrm{pH}$-trigger, the animals $(n=3)$ were imaged longitudinally before and after, as well as 24,48 and 96 hours post injection of the material. For the investigation of the in vivo responsiveness of the hybrid system to exogenous $\mathrm{pH}$-triggering, the animals $(n=3)$ received repeated s.c. injection ( 3 injections of $100 \mu l$ in a 10 minutes interval) of physiological solution with a defined pH 4 or 7.4 solution (Sterofundin $®$ (B. Braun Melsungen, Germany, adjusted with $\mathrm{NaOH}$ or $\mathrm{HCl}$ ) in the material injection site using a dwelling cannula. The mice were again imaged longitudinally before and after injection of the hybrid system, repeatedly during and shortly after the $\mathrm{pH}$-triggering, as well as 24 and 72 hours post intervention. The behavior, body weight and the skin area 
of the injection site were monitored to detect any adverse reaction during the investigation

period.

The imaging was carried out employing the IVIS ${ }^{\circledR}$ apparatus and the Living Image ${ }^{\circledR} 3.1$

software. Images were obtained using excitation/emission filters of $465 \mathrm{~nm}$ and Cy5.5, respectively. The exposure time was set to $0.25 \mathrm{~min}$. The images shown in the manuscript are the result of the overlay of bright field and fluorescent images. The final visualization was carried out in conditions of deep anesthesia, which were achieved by i.p. injection of medetomidine (1 mg/kg BW (Cepetor ${ }^{\circledR}$, CP-Pharma, Germany)) and ketamine $(75 \mathrm{mg} / \mathrm{kg}$ BW (Inresa Arzneimittel, Germany)). Animals were terminated afterwards by cervical dislocation and the injections site was harvested, inverted and imaged using the IVIS ${ }^{\circledR}$ as well as prepared for histological analysis.

Histological analysis of injection sites from mice. The explanted injection sites were extended in histological embedding cassettes (Tissue-Tec, Sacura Finetec USA, CA) and tissue was fixated in 4\% PFA for $24 \mathrm{~h}$. Consecutively, tissues were dehydrated and embedded in paraffin in $5 \mu \mathrm{m}$ sections and were stained with hematoxylin and eosin (H\&E) to analyze the corresponding tissue and the injected hybrid systems. Bright field images are shown at given magnifications (10x and 40x). 
Statistical analyses. The results shown throughout the manuscript are displayed as mean \pm SEM, unless otherwise stated. Statistical evaluation was carried out using nonparametric Kruskal-Wallis test and post hoc Dunn's test or two-tailed student's t-test, when applicable. $p<0.05$ was considered to be significant.

\section{ASSOCIATED CONTENT}

Supporting Information. Description of the analytical methods; Schematic synthesis of self-immolative polymers (Scheme S1) and their ${ }^{1} \mathrm{H}-\mathrm{NMR}$ characterization (Figures $\mathrm{S} 1$ to S3); SAXS of pristine C3 and C1Sph (Figure S4); $\mathrm{N}_{2}$ adsorption-desorption isotherms of pristine C3 and C1Sph at $77 \mathrm{~K}$ (Figure S5); XPS analysis of pristine C3 and C1Sph (Figure S6); Grafting protocol (Scheme S2); TEM images of pristine and SIP-coated C3 and C1Sph (Figure S7); Thermogravimetric analysis and $\mathrm{N}_{2}$ adsorption-desorption measurements/pore size distributions of the SIP-coated vs. pristine C3 and C1Sph (Figures S8 to S11); Colloidal stability of pristine and SIP-coated C3 and C1Sph (Figure S12); Thermal stability of SIP-coated C3 and C1Sph (Figure S13); Grafting density; XPS 
analysis of hybrid materials (Table S1); XPS survey of plain and SIP-coated C3 and

C1Sph (Figure S14).

\section{AUTHOR INFORMATION}

\section{Corresponding Author}

*Katharina Schmidt-Bleek (Katharina.Schmidt-Bleek@charite.de)

Julius Wolff Institute and Center for Musculoskeletal Surgery, CharitéUniversitätsmedizin Berlin, Berlin, Germany.

Berlin-Brandenburg School for Regenerative Therapies, Charité — Universitätsmedizin

Berlin, Berlin, Germany.

*Georgia Charalambopoulou (gchar@ipta.demokritos.gr)

National Center for Scientific Research "Demokritos", 15341 Agia Paraskevi Attikis, Athens, Greece.

*María Vallet-Regí (vallet@ucm.es) 
Department of Chemistry in Pharmaceutical Sciences, Faculty of Pharmacy, Universidad Complutense de Madrid, Instituto de Investigación Sanitaria Hospital 12 de Octubre (imas12), Plaza Ramón y Cajal s/n, 28040 Madrid, Spain.

Networking Research Center on Bioengineering, Biomaterials and Nanomedicine (CIBER-BBN), Madrid, Spain.

\section{Author Contributions}

The manuscript was written through contributions of all authors. All authors have given approval to the final version of the manuscript. $¥$ These authors contributed equally.

\section{Funding Sources}

This project has received funding from the European Union's Horizon 2020 research and innovation programme under grant agreement No 685872 (MOZART) and the European Research Council, ERC-2015 AdG (VERDI), Proposal No. 694160.

\section{ACKNOWLEDGMENT}


This project has received funding from the European Union's Horizon 2020 research and innovation programme under grant agreement No 685872 (MOZART) and the European Research Council, ERC-2015 AdG (VERDI), Proposal No. 694160. The authors would also like to express their gratitude to Dr. Carsten Grötzinger, Charité Universitätsmedizin Berlin, Germany, for instrumental support by enabling the usage of the in vivo imaging system (IVIS).

\section{REFERENCES}

(1) Min, Y.; Caster, J. M.; Eblan, M. J.; Wang, A. Z. Clinical Translation of Nanomedicine. Chem. Rev. 2015, 115, 11147-11190.

(2) Webster, T. J. Nanomedicine: What's in a Definition? Int. J. Nanomedicine 2006, 1, $115-116$.

(3) Shi, J.; Kantoff, P. W.; Wooster, R.; Farokhzad, O. C. Cancer Nanomedicine:

Progress, Challenges and Opportunities. Nat. Rev. Cancer 2017, 17, 20-37.

(4) Li, Y.; Xiao, Y.; Liu, C. The Horizon of Materiobiology: A Perspective on MaterialGuided Cell Behaviors and Tissue Engineering. Chem. Rev. 2017, 117, 4376- 
4421.

(5) Ragelle, H.; Danhier, F.; Préat, V.; Langer, R.; Anderson, D. G. Nanoparticle-Based

Drug Delivery Systems: A Commercial and Regulatory Outlook as the Field Matures. Expert Opin. Drug Deliv. 2017, 14, 851-864.

(6) Duncan, R.; Gaspar, R. Nanomedicine(s) under the Microscope. Mol. Pharm. 2011, $8,2101-2141$.

(7) Ji, P.; Zhou, B.; Zhan, Y.; Wang, Y.; Zhang, Y.; Li, Y.; He, P. Multistimulative Nanogels with Enhanced Thermosensitivity for Intracellular Therapeutic Delivery. ACS Appl. Mater. Interfaces 2017, 9, 39143-39151.

(8) Li, Y.; Maciel, D.; Rodrigues, J.; Shi, X.; Tomás, H. Biodegradable Polymer Nanogels for Drug/Nucleic Acid Delivery. Chem. Rev. 2015, 115, 8564-8608.

(9) Vallet-Regí, M.; Rámila, A.; Real, R. P. del; Pérez-Pariente, J. A New Property of MCM-41: Drug Delivery System. Chem. Mater. 2001, 13, 308-311.

(10) Manzano, M.; Vallet-Regí, M. New Developments in Ordered Mesoporous Materials for Drug Delivery. J. Mater. Chem. 2010, 20, 5593-5604.

(11) Vallet-Regí, M.; Manzano, M.; González-Calbet, J. M.; Okunishi, E. Evidence of 
Drug Confinement into Silica Mesoporous Matrices by STEM Spherical Aberration

Corrected Microscopy. Chem. Commun. 2010, 46, 2956-2958.

(12) Baeza, A.; Manzano, M.; Colilla, M.; Vallet-Regí, M. Recent Advances in Mesoporous Silica Nanoparticles for Antitumor Therapy: Our Contribution. Biomater. Sci. 2016, 4, 803-813.

(13) Kim, D.; Jin, S. H.; Jeong, S.; Lee, B.; Kang, K.; Lee, C. Microfluidic Preparation of Monodisperse Polymeric Microspheres Coated with Silica Nanoparticles. Sci. Rep. $2018,8,8528$.

(14) Luo, W.; Xu, X.; Zhou, B.; He, P.; Li, Y.; Liu, C. Formation of Enzymatic/RedoxSwitching Nanogates on Mesoporous Silica Nanoparticles for Anticancer Drug Delivery. Mater. Sci. Eng. C 2019, 100, 855-861.

(15) Gisbert-Garzarán, M.; Manzano, M.; Vallet-Regí, M. Mesoporous Silica Nanoparticles for the Treatment of Complex Bone Diseases: Bone Cancer, Bone Infection and Osteoporosis. Pharmaceutics 2020, 12, 83.

(16) Sayed, E.; Karavasili, C.; Ruparelia, K.; Haj-ahmad, R.; Charalambopoulou, G.; Steriotis, T.; Giasafaki, D.; Cox, P.; Singh, N.; Giassafaki, L. N.; et al. 
Electrosprayed Mesoporous Particles for Improved Aqueous Solubility of a Poorly Water Soluble Anticancer Agent: In Vitro and Ex Vivo Evaluation. J. Control. Release 2018, 278, 142-155.

(17) Yan, A.; Lau, B. W.; Weissman, B. S.; Külaots, I.; Yang, N. Y. C.; Kane, A. B.; Hurt, R. H. Biocompatible, Hydrophilic, Supramolecular Carbon Nanoparticles for Cell Delivery. Adv. Mater. 2006, 18, 2373-2378.

(18) Kim, T.; Chung, P.; Slowing, I. I.; Tsunoda, M.; Yeung, E. S.; Lin, V. S. Structurally Ordered Mesoporous Carbon Nanoparticles as Transmembrane Delivery Vehicle in Human Cancer Cells. Nano Lett. 2008, 8, 3724-3727.

(19) Gu, J.; Su, S.; Li, Y.; He, Q.; Shi, J. Hydrophilic Mesoporous Carbon Nanoparticles as Carriers for Sustained Release of Hydrophobic Anti-Cancer Drugs. Chem. Commun. 2011, 47, 2101-2103.

(20) Saha, D.; Warren, K. E.; Naskar, A. K. Soft-Templated Mesoporous Carbons as Potential Materials for Oral Drug Delivery. Carbon 2014, 71, 47-57.

(21) Huang, X.; Wu, S.; Du, X. Gated Mesoporous Carbon Nanoparticles as Drug Delivery System for Stimuli-Responsive Controlled Release. Carbon 2016, 101, 
$135-142$.

(22) Sánchez-Sánchez, Á.; Suárez-García, F.; Martínez-Alonso, A.; Tascón, J. M. D.

PH-Responsive Ordered Mesoporous Carbons for Controlled Ibuprofen Release.

Carbon 2015, 94, 152-159.

(23) Wang, Y.; Sun, Y.; Wang, J.; Yang, Y.; Li, Y.; Yuan, Y.; Liu, C. Charge-Reversal

APTES-Modified Mesoporous Silica Nanoparticles with High Drug Loading and

Release Controllability. ACS Appl. Mater. Interfaces 2016, 8, 17166-17175.

(24) Zhang, Y.; Han, L.; Zhang, Y.; Chang, Y.-Q.; Chen, X.-W.; He, R.-H.; Shu, Y.;

Wang, J.-H. Glutathione-Mediated Mesoporous Carbon as a Drug Delivery

Nanocarrier with Carbon Dots as a Cap and Fluorescent Tracer. Nanotechnology

2016, 27, 355102 .

(25) Zhang, Y.; Han, L.; Hu, L.-L.; Chang, Y.-Q.; He, R.-H.; Chen, M.-L.; Shu, Y.; Wang,

J.-H. Mesoporous Carbon Nanoparticles Capped with Poly(Acrylic Acid) as Drug

Carrier for Bi-Trigger Continuous Drug Release. J. Mater. Chem. B 2016, 4, 5178-

5184.

(26) Wan, L.; Jiao, J.; Cui, Y.; Guo, J.; Han, N.; Di, D.; Chang, D.; Wang, P.; Jiang, T.; 
Wang, S. Hyaluronic Acid Modified Mesoporous Carbon Nanoparticles for Targeted

Drug Delivery to CD44-Overexpressing Cancer Cells. Nanotechnology 2016, 27, 135102.

(27) Zhou, L.; Dong, K.; Chen, Z.; Ren, J.; Qu, X. Near-Infrared Absorbing Mesoporous Carbon Nanoparticle as an Intelligent Drug Carrier for Dual-Triggered Synergistic Cancer Therapy. Carbon 2015, 82, 479-488.

(28) Zhang, S.; Qian, X.; Zhang, L.; Peng, W.; Chen, Y. Composition-Property Relationships in Multifunctional Hollow Mesoporous Carbon Nanosystems for $\mathrm{PH}-$ Responsive Magnetic Resonance Imaging and on-Demand Drug Release. Nanoscale 2015, 7, 7632-7643.

(29) Zhang, L.; Li, Y.; Jin, Z.; Chan, K. M.; Yu, J. C. Mesoporous Carbon/CuS Nanocomposites for PH-Dependent Drug Delivery and near-Infrared ChemoPhotothermal Therapy. RSC Adv. 2015, 5, 93226-93233.

(30) Wang, H.; Sun, Y.; Yi, J.; Fu, J.; Di, J.; del Carmen Alonso, A.; Zhou, S. Fluorescent Porous Carbon Nanocapsules for Two-Photon Imaging, NIR/PH Dual-Responsive Drug Carrier, and Photothermal Therapy. Biomaterials 2015, 53, 117-126. 
(31) Zhu, S.; Chen, C.; Chen, Z.; Liu, X.; Li, Y.; Shi, Y.; Zhang, D. Thermo-Responsive Polymer-Functionalized Mesoporous Carbon for Controlled Drug Release. Mater. Chem. Phys. 2011, 126, 357-363.

(32) Mohapatra, S.; Rout, S. R.; Das, R. K.; Nayak, S.; Ghosh, S. K. Highly Hydrophilic Luminescent Magnetic Mesoporous Carbon Nanospheres for Controlled Release of Anticancer Drug and Multimodal Imaging. Langmuir 2016, 32, 1611-1620.

(33) Gisbert-Garzarán, M.; Manzano, M.; Vallet-Regí, M. PH-Responsive Mesoporous Silica and Carbon Nanoparticles for Drug Delivery. Bioengineering 2017, 4.

(34) Feng, S.; Mao, Y.; Wang, X.; Zhou, M.; Lu, H.; Zhao, Q.; Wang, S. Triple StimuliResponsive ZnO Quantum Dots-Conjugated Hollow Mesoporous Carbon Nanoplatform for NIR-Induced Dual Model Antitumor Therapy. J. Colloid Interface Sci. 2020, 559, 51-64.

(35) Cai, X.; Yan, H.; Luo, Y.; Song, Y.; Zhao, Y.; Li, H.; Du, D.; Lin, Y. Mesoporous Carbon Nanospheres with $\mathrm{ZnO}$ Nanolids for Multimodal Therapy of Lung Cancer. ACS Appl. Bio Mater. 2018, 1, 1165-1173.

(36) Asgari, S.; Pourjavadi, A.; Hosseini, S. H.; Kadkhodazadeh, S. A PH-Sensitive 
Carrier Based-on Modified Hollow Mesoporous Carbon Nanospheres with CalciumLatched Gate for Drug Delivery. Mater. Sci. Eng. C 2020, 109, 110517.

(37) Zhao, Q.; Lin, Y.; Han, N.; Li, X.; Geng, H.; Wang, X.; Cui, Y.; Wang, S. Mesoporous

Carbon Nanomaterials in Drug Delivery and Biomedical Application. Drug Deliv. 2017, 24, 94-107.

(38) Sagi, A.; Weinstain, R.; Karton, N.; Shabat, D. Self-Immolative Polymers. J. Am.

Chem. Soc. 2008, 8, 5434-5435.

(39) Gisbert-Garzarán, M.; Manzano, M.; Vallet-Regí, M. Self-Immolative Chemistry in Nanomedicine. Chem. Eng. J. 2017, 340, 24-31.

(40) Gisbert-Garzarán, M.; Lozano, D.; Vallet-Regí, M.; Manzano, M. Self-Immolative Polymers as Novel PH-Responsive Gate Keepers for Drug Delivery. RSC AdV. 2017, 7, 132-136.

(41) Karavasili, C.; Amanatiadou, E. P.; Sygellou, L.; Giasafaki, D. K.; Steriotis, T. A.; Charalambopoulou, G. C. Development of New Drug Delivery System Based on Ordered Mesoporous Carbons: Characterisation and Cytocompatibility Studies. J. Mater. Chem. B 2013, 1, 3167-3174. 
(42) Giasafaki, D.; Bourlinos, A.; Charalambopoulou, G.; Stubos, A.; Steriotis, T. Synthesis and Characterisation of Nanoporous Carbon-Metal Composites for Hydrogen Storage. Microporous Mesoporous Mater. 2012, 154, 74-81.

(43) Giasafaki, D.; Bourlinos, A.; Charalambopoulou, G.; Stubos, A.; Steriotis, T. Nanoporous Carbon - Metal Composites for Hydrogen Storage. Cent. Eur. J. Chem. $2011,9,948-952$.

(44) Ryoo, R.; Joo, S. H.; Jun, S. Synthesis of Highly Ordered Carbon Molecular Sieves via Template-Mediated Structural Transformation. J. Phys. Chem. B 1999, 103, 7743-7746.

(45) Benne, D.; Maccallini, E.; Rudolf, P.; Sooambar, C.; Prato, M. X-Ray Photoemission Spectroscopy Study on the Effects of Functionalization in Fulleropyrrolidine and Pyrrolidine Derivatives. Carbon 2006, 44, 2896-2903.

(46) Briggs, D. Surface Analysis of Polymers by XPS and Static SIMS; Briggs, D., Ed.; Cambridge Solid State Science Series; Cambridge University Press: Cambridge, 1998.

(47) Nie, Y.; Wang, W. N.; Jiang, Y.; Fortner, J.; Biswas, P. Crumpled Reduced 
Graphene Oxide-Amine-Titanium Dioxide Nanocomposites for Simultaneous Carbon Dioxide Adsorption and Photoreduction. Catal. Sci. Technol. 2016, 6, 61876196.

(48) Spyrou, K.; Calvaresi, M.; Diamanti, E. K.; Tsoufi, T.; Gournis, D.; Rudolf, P.; Zerbetto, F. Graphite Oxide and Aromatic Amines : Size Matters. Adv. Funct. Mater.

2014, 25, 263-269.

(49) Ederer, J.; Janoš, P.; Ecorchard, P.; Tolasz, J.; Štengl, V.; Beneš, H.; Perchacz, M.; Pop-Georgievski, O. Determination of Amino Groups on Functionalized Graphene Oxide for Polyurethane Nanomaterials: XPS Quantitation vs. Functional Speciation. RSC Adv. 2017, 7, 12464-12473.

(50) VanDelinder, V.; Wheeler, D. R.; Small, L. J.; Brumbach, M. T.; Spoerke, E. D.; Henderson, I.; Bachand, G. D. Simple, Benign, Aqueous-Based Amination of Polycarbonate Surfaces. ACS Appl. Mater. Interfaces 2015, 7, 5643-5649.

(51) Moulder, J. F.; William F. Stickle; Sobol, P. E.; Bomben, K. D. Handbook of X-Ray Photoelectron Spectroscopy, Perkin-Emler Corporation, 1992.

(52) Juárez, L. A.; Añón, E.; Giménez, C.; Sancenón, F.; Martínez-Máñez, R.; Costero, 
A. M.; Gaviña, P.; Parra, M.; Bernardos, A. Self-Immolative Linkers as Caps for the Design of Gated Silica Mesoporous Supports. Chem. - A Eur. J. 2016, 22, 1412614130.

(53) Niedermayer, S.; Weiss, V.; Herrmann, A.; Schmidt, A.; Datz, S.; Müller, K.; Wagner, E.; Bein, T.; Bräuchle, C. Multifunctional Polymer-Capped Mesoporous Silica Nanoparticles for PH-Responsive Targeted Drug Delivery. Nanoscale 2015, 7, 7953-7964.

(54) González-Alvarez, M.; Coll, C.; Gonzalez-Alvarez, I.; Giménez, C.; Aznar, E.; Martínez-Bisbal, M. C.; Lozoya-Agulló, I.; Bermejo, M.; Martínez-Máñez, R.; Sancenón, F. Gated Mesoporous Silica Nanocarriers for a "Two-Step" Targeted System to Colonic Tissue. Mol. Pharm. 2017, 14, 4442-4453.

(55) Martínez-Carmona, M.; Lozano, D.; Baeza, A.; Colilla, M.; Vallet-Regí, M. A Novel Visible Light Responsive Nanosystem for Cancer Treatment. Nanoscale 2017, 9, 15967-15973.

(56) Martínez-Carmona, M.; Lozano, D.; Colilla, M.; Vallet-Regí, M. Lectin-Conjugated PH-Responsive Mesoporous Silica Nanoparticles for Targeted Bone Cancer 
Treatment. Acta Biomater. 2018, 65, 393-404.

(57) Unfried, K.; Sydlik, U.; Bierhals, K.; Weissenberg, A.; Abel, J. Carbon NanoparticleInduced Lung Epithelial Cell Proliferation Is Mediated by Receptor-Dependent Akt Activation. Am. J. Physiol. Lung Cell. Mol. Physiol. 2008, 294, L358-67.

(58) Zanello, L. P.; Zhao, B.; Hu, H.; Haddon, R. C. Bone Cell Proliferation on Carbon Nanotubes. Nano Lett. 2006, 6, 562-567.

(59) Jun, S.; Joo, S. H.; Ryoo, R.; Kruk, M.; Jaroniec, M.; Liu, Z.; Ohsuna, T.; Terasaki, O. Synthesis of New, Nanoporous Carbon with Hexagonally Ordered Mesostructure. J. Am. Chem. Soc. 2000, 122, 10712-10713.

(60) Lu, A. H.; Li, W. C.; Schmidt, W.; Schüth, F. Template Synthesis of Large Pore Ordered Mesoporous Carbon. Microporous Mesoporous Mater. 2005, 80, 117-128.

(61) Shin, H. J.; Ryoo, R.; Jaroniec, M. Modification of SBA-15 Pore Connectivity by High-Temperature Calcination Investigated by Carbon Inverse Replication. Chem. Commun. 2001, 349-350.

(62) Zhao, D.; Zhao, D.; Feng, J.; Huo, Q.; Melosh, N.; Fredrickson, G. H.; Chmelka, B. F.; Stucky, G. D. Triblock Copolymer Syntheses of Mesoporous Silica with Periodic 
50 to 300 Angstrom Pores Triblock Copolymer. Science (80-. ). 1998, 279, 548-

552.

(63) Stöber, W.; Fink, A.; Bohn, E. Controlled Growth of Monodisperse Silica Spheres

in the Micron Size Range. J. Colloid Interface Sci. 1968, 26, 62-69.

(64) Baeza, A.; Guisasola, E.; Torres-Pardo, A.; González-Calbet, J. M.; Melen, G. J.;

Ramírez, M.; Vallet-Regí, M. Hybrid Enzyme-Polymeric Capsules/Mesoporous

Silica Nanodevice for in Situ Cytotoxic Agent Generation. Adv. Funct. Mater. 2014, 24, 4625-4633.

(65) Robbins, J. S.; Schmid, K. M.; Phillips, S. T. Effects of Electronics, Aromaticity, and Solvent Polarity on the Rate of Azaquinone-Methide-Mediated Depolymerization of Aromatic Carbamate Oligomers. J. Org. Chem. 2013, 78, 3159-3169.

(66) Lin, C.; Stedronsky, E. R.; Regen, S. L. PKa-Dependent Facilitated Transport of CO2 across Hyperthin Polyelectrolyte Multilayers. ACS Appl. Mater. Interfaces 2017, 9, 19525-19528.

Graphical abstract 


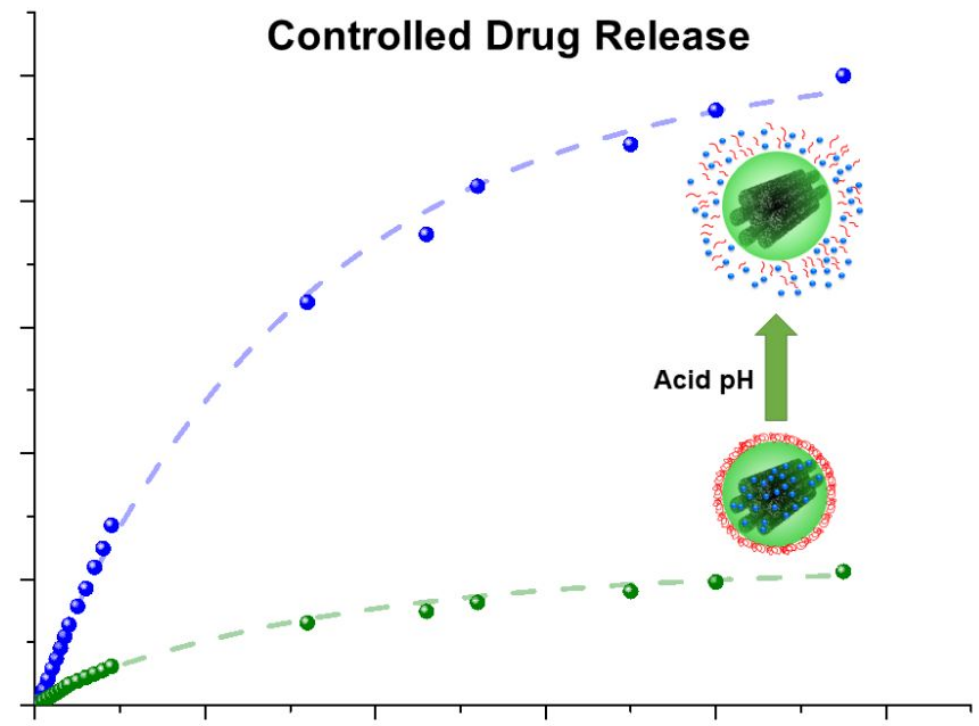

